\title{
The overlooked background of gastric MMC III: the signalling pathways of motilin receptors inducing canine left gastric artery relaxation
}

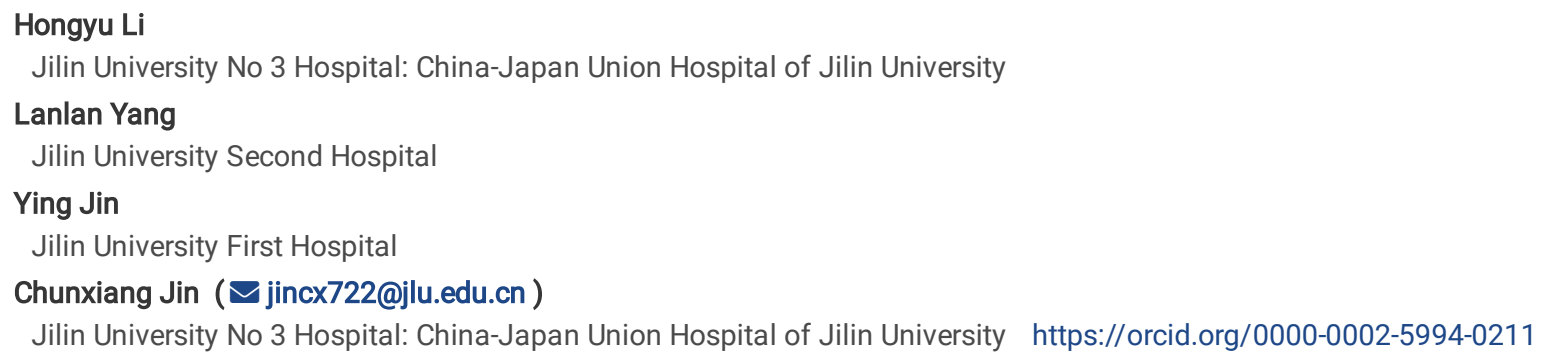

Original investigation

Keywords: canine left gastric artery, motilin receptor, multi-wire myograph system, relaxation, signal transduction

Posted Date: October 26th, 2020

DOl: https://doi.org/10.21203/rs.3.rs-93414/v1

License: (c) (i) This work is licensed under a Creative Commons Attribution 4.0 International License. Read Full License 


\section{Abstract}

Background: In diabetic patients with gastroparesis, the gastric blood supply is often decreased and delayed gastric emptying associating MMCIII absence is the main symptom. Under physiological conditions, motilin has been shown to induce a sustained increase in left gastric artery (LGA) blood flow and initiate MMC phase III simultaneously. The study aimed to elucidating the signal transduction pathways of motilin receptors (MLNRs) in the relaxation of LGA.

Methods: MLNR expression in the LGA was analysed by immunohistochemistry. Motilin-induced relaxation of the LGA was tested in a multi-wire myograph system. Effects of inhibitors or blockers in the signal transduction pathway were observed.

Results: Immunohistochemical and immunofluorescence staining showed that the MLNRs were on the membranes of endothelial cells. Motilin relaxed U46619 pre-contracted canine LGA rings in a concentration-dependent manner, with an EC50 value of $9.010 \pm 0.789 \times 10^{-8} \mathrm{M}$. Motilin's effect was inhibited by denuded endothelium but not by muscarinic receptor inhibitors. The effect was selectively and competitively inhibited by Phe-cyclo[Lys$\operatorname{Tyr}(3-\mathrm{tBu}$ )-Ala-]•trifluoroacetate (GM-109; MLNR antagonist) and completely or partially inhibited by inhibitors of the G protein-phospholipase Cinositol trisphosphate (G pr-PLC-IP 3 ) and nitric oxide synthase-nitric oxide-soluble guanylyl cyclase (NOS-NO-sGC) signal transduction pathway, inhibitors of cyclooxygenase and myoendothelial gap junction, blockers of the potassium channel and low/free $\mathrm{Ca}^{2+} \mathrm{Krebs}$ solutions, but not by inhibitors of protein kinase $\mathrm{C}$, protein kinase $\mathrm{A}$ or L-type voltage-operated $\mathrm{Ca}^{2+}$ channel.

Conclusions: MLNRs were on the membranes of endothelial cells of canine LGA. The main intracellular signal transduction pathway was motilinMLNR-G pr-PLC-IP $3-$ NOS-NO-sGC-cGMP. These results may provide a new theoretical basis for research on diabetic gastroparesis.

\section{Background}

Gastrointestinal blood supply is no doubt the basic and important background of all the gastrointestinal activities [1]. Gastrointestinal tract is one of the most susceptible organ systems to ischaemia. In diabetic patients with gastroparesis, the gastric blood supply is often decreased [2], in which delayed gastric emptying associating migrating motor complex phase III (MMC III) absence without a mechanical obstruction is the main symptom [3] However, how the gastric arteries work in this process have not been fully understand.

The MMC is a cyclic, recurring motility pattern that occurs in the stomach and small bowel during fasting. It consists of four phases of which phase III is the most prominent phase characterized by a burst of contractions of maximal amplitude [4]. About $70 \%$ of measured spontaneous phase III contractions in healthy volunteers start in the stomach [5]. Motilin has been found to induce the premature gastric MMC phase III during fasting in such species like man and dog [6-9]. Motilin is mainly produced by endocrine cells of the proximal small intestine [10], and its plasma levels fluctuate with interdigestive motility and are maximal during gastric phase III [11]. Under physiological conditions, motilin has been shown to induce a sustained increase in left gastric artery (LGA) blood flow ( $\leq 240 \%$ resting blood flow) and initiate MMC phase III simultaneously [12]. The periodically diastolic LGA induced by motilin not only supply sufficient blood to the gastric wall to prevent gastric mucosal ischaemia even under the strongest contraction during the interdigestive period [11, 13], but also delivers amounts of gastrointestinal hormones such as motilin to the stomach's target receptors to activate gastric MMC phase III. Thus, a clear understanding of the role of motilin receptor (MLNR) mediated intracellular signal transduction in the regulation of gastric arterial blood flow will greatly enrich relevant theories on the regulation of gastrointestinal activities.

The effects of motilin to relax LGA of dogs can be completely inhibited by GM-109 [12]. Therefore, MLNRs must exist on the walls of canine gastric arteries. The vessel wall is no doubly a new site for GM-109-sensitive MLNRs, besides the myenteric plexus [14, 15], gastrointestinal smooth muscle $[16,17]$, brain [18, 19], thyroid and bone marrow [20]. However, there has been no directly evidence. MLNR identified in the human stomach is GPR38-A, which is a member of the G protein (G pr)-coupled receptor (GPCR) family [20]. G proteins located in cell membrane interact with the cytoplasmic GPCR loops in the presence of agonists, thereby transducing signalling to downstream effectors such as adenylate cyclase (AC) and phospholipase $C$ (PLC). Activation of these molecules generates several important secondary messengers, including inositol triphosphate $\left(\mathrm{IP}_{3}\right)$ and diacylglycerol $(\mathrm{DG})$, which in turn regulate a range of physiological cellular responses [21]. In HEK-293/aeq17 cells transfected with MLNR [20] and in the smooth muscle cells of the rabbit stomach and intestine [22, 21] and those of the rat stomach [23], the intracellular signal transduction pathway was identified as the motilinMLNR-G pr-PLC-IP 3 , in which motilin or MLNR agonists led to the increase of intracellular $\mathrm{Ca}^{2+}$, and the potential contribution of the protein kinase $\mathrm{C}$ (PKC) pathway was excluded. These studies provide an important reference for the investigation of intracellular signal transduction mechanisms in motilin-induced increase of blood flow in canine LGA.

Motilin-induced relaxation of porcine coronary artery [24] and canine mesenteric artery [25] was shown to be closely related to nitric oxide (NO). NO is the most important endothelium-dependent vasodilator. In dogs, acetylcholine is thought to be the final mediator in motilin signalling [26, 27]. Furthermore, acetylcholine is a powerful agent to promote the release of NO from vascular endothelial cells [28]. Therefore, the role of endothelial cells and acetylcholine in motilin-induced relaxation of LGA must be clarified. In addition to NO, endothelial cells release other relaxation factors such as prostacyclin $\left(\mathrm{PGI}_{2}\right)$ and endothelium-dependent hyperpolarisation factor (EDHF). The effects of $\mathrm{PGI}_{2}$ and EDHF are inversely proportional to the integrity of the NO system and the diameter of the blood vessel $[29,30]$. Specifically, EDH is associated with myoendothelial gap junctions (MEGJ) and potassium channels [29]. Moreover, $\mathrm{Ca}^{2+}$ ions play important roles in motilin-induced vasodilatation, including the effects of extracellular $\mathrm{Ca}^{2+}$ ions and $\mathrm{Ca}^{2+}$ channels [24]. All these above factors may be involved in motilin-induced relaxation of LGA and remains to be explored. 
The research on how the gastric arteries periodically deliver motilin from proximal small intestine to the targeted MLNRs on the stomach are uncommon. In the present study, considering the complexity of signalling pathways of artery relaxation, which simultaneously involves both the endothelial cells and smooth muscle cells, freshly isolated intact LGAs from healthy dogs were mounted in a multi-wire myograph system. Thereafter, inhibitors or blockers of the intracellular signalling transduction pathways were used to investigate the intracellular mechanisms of motilin-induced LGA relaxation. The ultimate purpose of understanding these mechanisms is to prevent or delay the progression of diabetic vascular complications and improve the quality of life in these patients.

\section{Methods}

\section{Preparation of Canine LGA}

After an overnight fast, 96 mongrel adult healthy dogs of either sex, weighing 15-30 kg, obtained from the Section of Surgical Teaching, Jilin University, were sacrificed by rapid exsanguination from the common carotid artery under deep anaesthesia with sodium pentobarbital (30 mg $\mathrm{kg}^{-1}$, i.v.). The connective tissues and fat were carefully dissected under a dissecting microscope (SZ61, Olympus, Japan) avoiding over-pulling and clamping.

\section{Immunostaining of MLNR}

\section{Immunohistochemical staining of MLNR}

The LGAs were procured from six dogs. The paraffin-embedded tissues were cut into 4- $\mu$ m sections, deparaffinised, rehydrated, boiled in retrieval solution and washed in PBS. After blocking in normal horse serum for 30 min, the sections were incubated with rabbit anti-dog MLNR antibody (1:100; RaQualia Pharma Inc., Taketoyo, Japan) overnight at $4^{\circ} \mathrm{C}$ [14]. The next day, the sections were incubated with biotinylated goat anti-rabbit antibody (Sigma, St. Louis, MO, USA) and horseradish peroxidase-conjugated avidin (Sigma, Shanghai, China) for 30 min at room temperature. The stained sections were then visualised using 3,3'-diaminobenzidine (Sigma, St. Louis, MO, USA). For negative controls, the primary antibody was replaced with affinity-purified pre-immune lgG.

\section{Immunofluorescence staining of MLNR}

The LGAs were procured from three dogs. The $6-\mu \mathrm{m}$ paraffin-embedded sections were deparaffinised, incubated in $0.1 \%$ Triton $\mathrm{X}-100$ at $4{ }^{\circ} \mathrm{C}$ for $1 \mathrm{~h}$ and washed three times with PBS. After 5-min digestion with proteinase K, the sections were washed with PBS and blocked in $5 \%$ normal goat serum for 30 min. Subsequently, the sections were incubated with rabbit anti-dog MLNR antibody (1:100, RaQualia Pharma Inc., Taketoyo, Japan) and mouse antidog cluster of differentiation 34 (CD34) antibody (1:100; Affymetrix, Santa Clara, CA, USA) overnight at $4^{\circ} \mathrm{C}$. After three 10-min washes with PBS, the sections were incubated with fluorescein isothiocyanate-labelled (green) goat anti-rabbit immunoglobulin (Ig)G (1:50; Abbkine, California, USA) and Cy3-labelled (red) goat anti-mouse IgG (1:100; Abbkine, California, USA) for $1 \mathrm{~h}$ at room temperature. The sections were washed again three times with PBS for 10 min, incubated with Hoechst 33342 (Sigma, Shanghai, China) for nuclear staining for 5 min, washed twice with PBS for 5 min each and finally mounted. The slides were visualised and photographed under a confocal microscope (FV1000; Olympus, Tokyo, Japan). For negative controls, the primary antibody was replaced with affinity-purified pre-immune IgG. All images were processed using FV10-ASW 1.7 software (Olympus, Tokyo, Japan).

\section{Reagents}

Porcine motilin (Peptide Institute Inc., Osaka, Japan), acetylcholine chloride (ACh) (Sigma, Shanghai, China), GM-109 (Peptide Institute Inc.), atropine sulfate (Atropin; Neptunus, Shenzhen, China), N-nitro-L-arginine methyl ester (L-NAME) (Sigma), tetraethylammonium chloride (TEA) (Yuanye, Shanghai, China) and ethylene glycol tetra-acetic acid (EGTA) (Sigma) were dissolved in distilled water. N-ethylmaleimide (NEM) (Sigma) was dissolved in distilled water but shielded from light, and the $\mathrm{pH}$ was controlled between 7.0 and 7.35. U73122 (MCE, Shanghai, China), 2-aminoethyl diphenylborinate (2-APB) (Sigma), chelerythrine chloride (MCE), (N-2-[p-bromocinnamylamino]ethyl)-5-isoquinolinesulfonamidehydrochloride (H89) (MCE), 1H-[1,2,4]oxadiazolo[4,3-a]quinoxalin-1-one (ODQ) (Sigma), indomethacin (MCE), 18a-glycyrrhetinic acid (18a-GA) (Sigma), glibenclamide (MCE) and verapamil (MCE) were dissolved in dimethylsulfoxide (DMSO) (Solarbio, Beijing, China). U46619 (Sigma) was dissolved in $96 \%$ ethanol to $0.4 \mathrm{mM}$ stock and further diluted with distilled water before use. Concentrations refer to the final concentration of the drugs in the bath and are expressed as $\mathrm{mol} \mathrm{L}^{-1}(\mathrm{M})$. The DMSO and ethanol in the bath were set to $<0.4 \%$ and $0.1 \%(\mathrm{v} / \mathrm{v})$, respectively, which produced no changes in the tonus of the vascular preparations.

\section{Record of Isometric Vascular Tone}

Each LGA was approximately 18-30 mm long and was cut into six to ten 3-mm length rings which were immediately mounted between two L-shaped stainless-steel hooks (300 $\mathrm{mm}$ in diameter) in the organ bath of the multi-wire myograph system (DMT620, Demark). The organ bath contained a 5-mL modified Krebs-Henseleit bicarbonate buffer (Krebs solution) composed of $118.0 \mathrm{mM} \mathrm{NaCl}, 4.7 \mathrm{mM} \mathrm{KCl}, 2.5 \mathrm{mM} \mathrm{CaCl}_{2}, 1.2 \mathrm{mM} \mathrm{KH}_{2} \mathrm{PO}_{4}, 1.2 \mathrm{mM}$ $\mathrm{MgSO}_{4}, 25 \mathrm{mM} \mathrm{NaHCO}_{3}$ and $10 \mathrm{mM}$ glucose ( $\mathrm{pH}$ 7.4) [25] and continuously supplied with $95 \% \mathrm{O}_{2}$ and $5 \% \mathrm{CO}_{2}$. The temperature and pH of the buffer were maintained at $37^{\circ} \mathrm{C}$ and 7.40. Tension was recorded using LabChart Data Acquisition Software (LabChart 8.0; ADInstruments, Australia). The rings were passively stretched to a tension of approximately $15 \mathrm{mN}$, maintained for approximately 60 min and washed every 15 min. After stabilisation 
of the tension, the viability of the rings was assessed by $60 \mathrm{mM} \mathrm{KCl}(60 \mathrm{mM} \mathrm{KCl} \mathrm{Krebs} \mathrm{solution} \mathrm{made} \mathrm{by} \mathrm{replacing} \mathrm{NaCl}$ with equimolar $\mathrm{KCl})$ at least twice.

Subsequently, U46619 (a thromboxane $A_{2}$ analogue) $\left(5 \times 10^{-8} \mathrm{M}\right)$ was used. Once a sustained contract tension was reached, one concentration of motilin was examined to avoid tachyphylaxis [31]. Endothelium-denuded rings were made by gently scraping the endothelial cells with a pair of pointed metal forceps before mounting. In the inhibitor groups, the rings were first incubated with different inhibitors for 15-40 min before adding U46619; rings from the same LGA incubated with saline were considered as the control group. In the $\mathrm{Ca}^{2+}$-free Krebs solution, Ca ${ }^{2+}$ was replaced with $1 \mathrm{mM}$ EGTA. The endothelium integrity or functional removal was verified by acetylcholine $\left(10^{-5} \mathrm{M}\right)$ at the end of each test, with the relaxation rate (RR) $>80 \%$ or $<10 \%$, respectively.

The RR was expressed as a percentage decrease in the tension induced by U46619 and/or high-potassium solution according to the following formula:

$$
R R=100 \% \times(T-L) \times T^{-1}
$$

In the calculation of the inhibition rate (IR), the tension was normalised to the corresponding values of the control group:

$$
I R=100 \% \times[(T c-L c)-(T i-L i) \times T c / T i)] \times(T c-L c)^{-1},
$$

where $T$ is a sustained tension, $L$ is the lowest tension, i represents the inhibitor group and c represents the control group.

Concentration-response curves were analysed by nonlinear regression analysis with variable slopes in GraphPad Prism 6 (GraphPad Software, San Diego California, USA), from which the ECx (x\% maximal effective concentration) and Hillslope were obtained. The pA2 value was calculated according to the Van Rossum equation:

$$
p A 2=-\log A+\log (C R-1)
$$

where, $\mathrm{A}$ is the molar concentration of the antagonist and CR is the ratio of the EC50 value (EC50 with an antagonist/EC50 without an antagonist) [32].

\section{Measurement of NO and cGMP Levels in LGA}

Tissue collection and homogenisation were conducted based on the methods provided by Schachter et al [33]. LGAs from three dogs were pooled together to provide sufficient tissue for analysis at each time. When NO was detected, seven groups were created. Three groups were first incubated with $5 \times 10^{-8} \mathrm{M} \mathrm{U} 46619\left(5 \times 10^{-8} \mathrm{M}\right)$ followed by saline, motilin $\left(9 \times 10^{-8} \mathrm{M}\right)$ or acetylcholine $\left(10^{-5} \mathrm{M}\right)$ respectively. Four groups were incubated with GM109 $\left(10^{-5} \mathrm{M}\right)$, L-NAME $\left(10^{-4} \mathrm{M}\right), \mathrm{H} 89\left(5 \times 10^{-6} \mathrm{M}\right)$ or chelerythrine $\left(2 \times 10^{-6} \mathrm{M}\right)$ before $\mathrm{U} 46619\left(5 \times 10^{-8} \mathrm{M}\right)$ and motilin $\left(9 \times 10^{-8} \mathrm{M}\right)$ were added. When cGMP was detected, the groups were the same as those in which NO was detected, except that the ODQ $\left(10^{-5} \mathrm{M}\right)$ group was included. U46619 (5 $\left.\times 10^{-8} \mathrm{M}\right)$ was the negative group (blank column), motilin $\left(9 \times 10^{-8} \mathrm{M}\right)$ added after $\mathrm{U} 46619\left(5 \times 10^{-8} \mathrm{M}\right)$ was the positive control group (motilin column), inhibitors added before U46619 and motilin were the experimental groups and acetylcholine ( $\left.10^{-5} \mathrm{M}\right)$ was used to confirm the activity of endothelial cells (acetylcholine group).

Tissues were homogenised in the following solution: $10.0 \mathrm{mM}$ Tris-HCL, $0.1 \mathrm{mM}$ EDTA-2Na, $10 \mathrm{mM}$ sucrose and $136.7 \mathrm{mM} \mathrm{NaCl}$ (pH 7.4) in 1:9 ratio of weight $(\mathrm{g})$ to volume $(\mathrm{mL})$. The homogenate mixture was then centrifuged at $4^{\circ} \mathrm{C}, 2.4 \mathrm{~g}(5000 \mathrm{rpm})$ for 10 min, and the supernatant was used for detection. We strictly adhered to the protocol for the detection process. The total protein concentration was assayed using a bicinchoninic acid (BCA) total protein assay kit (A045-3; Jiancheng, Nanjing, China) and bovine serum albumin was used as the standard and expressed in $\mu \mathrm{mol} \mathrm{mL}^{-1}$. The cGMP concentration was assayed using a canine cGMP ELISA kit (Cat No. ela05471 Ca, SANCHEZ, Colorado, USA) and expressed in picomoles of

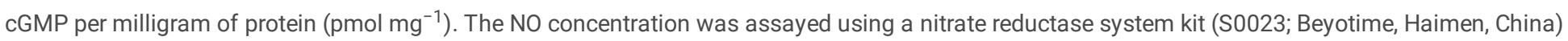
and expressed in micromoles of NO per gram of protein $\left(\mu \mathrm{mol} \mathrm{g}{ }^{-1}\right)$.

\section{Statistical Analysis}

All numerical data are presented as means \pm standard error of the mean (SEM) with $n$ equal to the number of dogs in the multi-wire myograph system and $\mathrm{N}$ equal to the number of repetitions in other experiments. Statistical analysis was performed using GraphPad Prism 6 (GraphPad Software). Data analyses were performed using a paired or unpaired $t$-test for paired or unpaired data, and one-way analysis of variance followed by Dunnett's posthoc test for multiple comparisons. $\mathrm{P}<0.05$ was considered statistically significant.

\section{Results}

\section{Location of MLNR Expression on Canine LGA}

Page $4 / 27$ 
Immunohistochemical staining revealed brown linear staining along the endothelium of LGA, but no brown staining in the negative control group ( $\mathrm{N}=$ 6) (Fig. 1a). Immunofluorescence double staining was performed using the CD34 (antibody of endothelial cell marker) and MLNR antibody after LGA sectioning, which showed that CD34 and MLNR completely overlapped ( $=3$ ) (Fig. 1b).

\section{Effects of Motilin on Isolated Canine LGA}

The dose-response curve of motilin $\left(10^{-9}-10^{-5} \mathrm{M}\right)$ showed a clear inverted ' $\mathrm{S}$ ' shape with an essentially linear middle section (Each $\mathrm{n}=7$; Fig. $\left.2 \mathrm{a}\right)$. The low concentrations of motilin $\left(10^{-9}-9 \times 10^{-9} \mathrm{M}\right)$ had almost no effect (Fig. 2b), medium concentrations of motilin (10-8 $\left.-9 \times 10^{-7} \mathrm{M}\right)$ had a clear dose-dependent diastolic effect on LGA (Fig. 2C-f) and high concentrations of motilin $\left(1 \times 10^{-6}, 3 \times 10^{-6}\right.$ and $\left.10^{-5} \mathrm{M}\right)$ had a very strong diastolic effect and almost reached the plateau (Fig. $2 \mathrm{~g}-\mathrm{i}$ ). The Emax was $73.73 \% \pm 1.834 \%$ and HillSlope was $0.873 \pm 0.068$. The calculated EC50 was $9.010 \times 10^{-8} \pm$ $0.789 \times 10^{-8} \mathrm{M}$, with a $95 \%$ confidence interval of $7.596 \times 10^{-8}$ to $1.069 \times 10^{-7} \mathrm{M}$. Therefore, further experiments were performed with motilin at $9 \times$ $10^{-8} \mathrm{M}$.

\section{Effects of Endothelial Denudation on the Motilin- or Acetylcholine-induced Vasorelaxation of LGA}

Endothelial denudation abolished the motilin-induced vasorelaxation. We also found that acetylcholine did not relax the preparations without endothelium. In summary, motilin-induced and acetylcholine-induced relaxation of LGA were both endothelium-dependent, as shown in Table 1. Representative images are shown in Fig. 3.

Table 1

The effects of endothelium-denudation and atropine on motilin- and acetylcholine-induced relaxation in canine LGA rings

\begin{tabular}{|c|c|c|c|c|c|c|c|c|c|c|c|c|}
\hline & \multirow[b]{2}{*}{$\mathbf{n}$} & \multirow[b]{2}{*}{ Function } & \multirow[b]{2}{*}{$\begin{array}{l}\text { Time } \\
(\min )\end{array}$} & \multirow[b]{2}{*}{ Concentration(M) } & \multicolumn{4}{|l|}{ Motilin } & \multicolumn{4}{|c|}{ Acetylcholine } \\
\hline & & & & & $\begin{array}{l}\text { RRc } \\
(\%)\end{array}$ & RRi (\%) & IR & $\begin{array}{l}\mathrm{P} \\
\text { value }\end{array}$ & $\begin{array}{l}\text { RRc } \\
(\%)\end{array}$ & RRi (\%) & $\operatorname{IR}(\%)$ & $\begin{array}{l}\mathrm{P} \\
\text { value }\end{array}$ \\
\hline $\begin{array}{l}\text { Endothelial } \\
\text { denudation }\end{array}$ & 7 & - & - & - & $\begin{array}{l}37.03 \% \\
\pm \\
1.89 \%\end{array}$ & $\begin{array}{l}4.08 \% \pm \\
0.50 \% \star \star \star\end{array}$ & $\begin{array}{l}88.42 \% \\
\pm \\
2.46 \%\end{array}$ & 0.0001 & $\begin{array}{l}88.77 \% \\
\pm \\
1.23 \%\end{array}$ & $\begin{array}{l}2.54 \% \pm \\
0.63 \% \text { *** }\end{array}$ & $\begin{array}{l}97.13 \% \\
\pm \\
0.69 \%\end{array}$ & $\begin{array}{l}< \\
0.0001\end{array}$ \\
\hline Atropin & 7 & $\begin{array}{l}\text { a MR } \\
\text { inhibitor }\end{array}$ & 15 & $10^{-5}$ & $\begin{array}{l}42.41 \% \\
\pm \\
4.00 \%\end{array}$ & $\begin{array}{l}39.18 \% \\
\pm 3.53 \%\end{array}$ & $\begin{array}{l}6.76 \% \\
\pm \\
4.75 \%\end{array}$ & 0.1563 & $\begin{array}{l}88.36 \% \\
\pm \\
1.61 \%\end{array}$ & $\begin{array}{l}1.50 \% \pm \\
1.30 \% * \star \star\end{array}$ & $\begin{array}{l}98.27 \% \\
\pm \\
1.44 \%\end{array}$ & $\begin{array}{l}< \\
0.0001\end{array}$ \\
\hline
\end{tabular}

RRc: relaxation rate of control group; RRi: relaxation rate of inhibitor group; IR: inhibition rate.

$\star \star \star P<0.001 ; * \star p<0.01 ; * \mathrm{p}<0.05$

\section{Effects of a Muscarinic Receptor (MR) Inhibitor on the Motilin- or Acetylcholine- induced Vasorelaxation of LGA}

After the pre-treatment of endothelium-intact rings with atropine (an MR inhibitor), motilin-induced relaxation did not decrease. As expected, atropine abolished the acetylcholine-induced vasorelaxation significantly. The results indicate that motilin-induced relaxation of LGA did not occur through muscarinic receptor. Data are summarised in Table 1 with representative images shown in Fig. 3.

\section{Effects of an MLNR Inhibitor (GM-109) on the Motilin-induced Vasorelaxation of LGA}

GM-109 $\left(10^{-10}-10^{-5} \mathrm{M}\right)(11$ concentrations, each $\mathrm{n}=7)$ inhibited motilin $\left(9 \times 10^{-8} \mathrm{M}\right)$-induced relaxation of LGA in a dose-dependent manner, with an IC50 value of $7.820 \times 10^{-8} \pm 0.647 \times 10^{-8} \mathrm{M}$ and a HillSlope of $0.8404 \pm 0.057$ (Fig. 4a).

GM-109 $\left(5 \times 10^{-8} \mathrm{M}\right)$ shifted the dose-response curve of motilin $\left(3 \times 10^{-9}-10^{-6} \mathrm{M}\right)$ parallel to the right $(\mathrm{n}=5)(\mathrm{Fig} .4 \mathrm{~b})$. The EC50 value $\left(8.555 \times 10^{-8}\right.$ $\pm 3.222 \times 10^{-8} \mathrm{M}$ and $2.713 \times 10^{-7} \pm 0.147 \times 10^{-7} \mathrm{M}$ for the GM-109-untreated and treated groups, respectively) and the maximum amplitude (75.57\% $\pm 10.72 \%$ and $87.57 \% \pm 43.14 \%$ for the GM-109-untreated and treated groups, respectively) did not significantly change. The pA2 value of GM-109 was calculated to be 7.638 .

Higher concentration of GM-109 $\left(10^{-5} \mathrm{M}\right)$ significantly inhibited motilin $\left(10^{-8}-10^{-6} \mathrm{M}\right)$-induced $(19$ concentrations, each $\mathrm{n}=5)$ relaxation of LGA, with IR values $>78.12 \% \pm 4.82 \%$ (Fig. 4c). We also found that GM-109 at $10^{-5} \mathrm{M}$ had no effect on the baseline, U46619-induced contraction and acetylcholine-induced relaxation in LGA rings (Fig. 4d).

Roles of the G pro-PLC-IP 3 Pathway, Protein Kinase C (PKC) or Protein Kinase A (PKA) in Motilin-induced Vasorelaxation of LGA

NEM (a sulfhydryl alkylating agent that uncouples G proteins) significantly decreased the motilin-induced relaxation of LGA. U73122, a PLC inhibitor, also significantly decreased the motilin-induced relaxation of LGA. At $3 \times 10^{-4} \mathrm{M}, 2-\mathrm{APB}$ (an IP ${ }_{3} \mathrm{R}$ and store-operated Ca ${ }^{2+}$ channel $[S 0 C C]$ blocker)

Page 5/27 
almost completely blocked the effect of motilin. The inhibitory effect of different concentrations of 2-APB on motilin-induced vasorelaxation in U46619 pre-contracted canine LGA rings and their representative original traces, see Fig. 5. Neither chelerythrine, a PKC inhibitor, nor H89, a PKA inhibitor, had an inhibitory effect on motilin-induced vasorelaxation, while both enhanced vasorelaxation. These results are summarised in Table 2 , and the representative images are shown in Fig. 6 
Table 2

The effects of inhibitors and blockers of G protein Signalling pathways, NOS-NO-sGC signalling pathway, cyclooxygenase products, EDH, L-type VOCC and extracellular $\mathrm{Ca}^{2+}$ on motilin- and acetylcholine-induced relaxation in canine LGA rings

\begin{tabular}{|c|c|c|c|c|c|c|c|c|}
\hline & $\mathbf{n}$ & Functions & $\begin{array}{l}\text { Time } \\
(\text { min) }\end{array}$ & $\begin{array}{l}\text { Concentration } \\
\text { (M) }\end{array}$ & $\operatorname{RRc}(\%)$ & RRi (\%) & $\operatorname{IR}(\%)$ & $\begin{array}{l}P \\
\text { value }\end{array}$ \\
\hline \multicolumn{9}{|c|}{ Effects of $G$ protein Signalling pathways inhibitors and blockers } \\
\hline \multirow[t]{2}{*}{ NEM } & 7 & $\begin{array}{l}\text { a sulfhydryl alkylating agent that } \\
\text { uncouples } G \text { proteins }\end{array}$ & 30 & $3 \times 10^{-5}$ & $\begin{array}{l}49.47 \% \pm \\
2.40 \%\end{array}$ & $\begin{array}{l}23.38 \% \pm \\
1.73 \%\end{array}$ & $\begin{array}{l}52.26 \% \pm \\
3.95 \%\end{array}$ & $<.0001$ \\
\hline & & & & & & $\star \star \star *$ & & \\
\hline \multirow[t]{2}{*}{ U73122 } & 7 & a PLC inhibitor & 40 & $10^{-5}$ & $\begin{array}{l}44.43 \% \pm \\
5.15 \%\end{array}$ & $\begin{array}{l}4.86 \% \pm \\
0.79 \%\end{array}$ & $\begin{array}{l}88.45 \% \pm \\
1.98 \%\end{array}$ & 0.0002 \\
\hline & & & & & & $\star \star \star$ & & \\
\hline \multirow[t]{2}{*}{ 2-APB } & 7 & an $\mathrm{IP}_{3} \mathrm{R}$ and SOCC blocker & 15 & $3 \times 10^{-4}$ & $\begin{array}{l}38.47 \% \pm \\
5.22 \%\end{array}$ & $\begin{array}{l}1.56 \% \pm \\
0.24 \%\end{array}$ & $\begin{array}{l}95.38 \% \pm \\
1.06 \%\end{array}$ & 0.0004 \\
\hline & & & & & & $\star \star \star$ & & \\
\hline Chelerythrine & 7 & a PKC inhibitor & 30 & $10^{-6}$ & $\begin{array}{l}34.9 \% \pm \\
2.91 \%\end{array}$ & $\begin{array}{l}39.65 \% \pm \\
3.72 \%\end{array}$ & $\begin{array}{l}-12.30 \% \pm \\
3.12 \%\end{array}$ & 0.0117 \\
\hline H89 & 7 & a PKA inhibitor & 30 & $5 \times 10^{-6}$ & $\begin{array}{l}35.68 \% \pm \\
3.34 \%\end{array}$ & $\begin{array}{l}36.76 \% \pm \\
3.52 \%\end{array}$ & $\begin{array}{l}-2.95 \% \pm \\
2.15 \%\end{array}$ & 0.1881 \\
\hline \multicolumn{9}{|c|}{ Effects of NOS-NO-sGC Signalling Pathway, Products of Cyclooxygenase and EDH inhibitors and blockers } \\
\hline \multirow[t]{2}{*}{ L-NAME } & 7 & a NOS inhibitor & 15 & $10^{-4}$ & $\begin{array}{l}35.49 \% \pm \\
4.07 \%\end{array}$ & $\begin{array}{l}3.21 \% \pm \\
0.63 \%\end{array}$ & $\begin{array}{l}90.81 \% \pm \\
1.48 \%\end{array}$ & 0.0001 \\
\hline & & & & & & $\star \star \star ~$ & & \\
\hline \multirow[t]{2}{*}{ ODQ } & 7 & a sGC inhibitor & 15 & $10^{-5}$ & $\begin{array}{l}36.09 \% \pm \\
3.75 \%\end{array}$ & $\begin{array}{l}3.43 \% \pm \\
0.53 \%\end{array}$ & $\begin{array}{l}90.23 \% \pm \\
1.59 \%\end{array}$ & 0.0001 \\
\hline & & & & & & $\star \star \star$ & & \\
\hline \multirow[t]{2}{*}{ Indomethacin } & 7 & a cyclooxygenase inhibitor & 20 & $10^{-5}$ & $\begin{array}{l}39.51 \% \pm \\
2.99 \%\end{array}$ & $\begin{array}{l}32.71 \% \pm \\
3.41 \%\end{array}$ & $\begin{array}{l}17.87 \% \pm \\
3.72 \%\end{array}$ & 0.0038 \\
\hline & & & & & & ** & & \\
\hline \multirow[t]{2}{*}{ 18a-GA } & 7 & a MEGJ inhibitor & 30 & $7.5 \times 10^{-5}$ & $\begin{array}{l}35.20 \% \pm \\
3.38 \%\end{array}$ & $\begin{array}{l}26.41 \% \pm \\
2.86 \%\end{array}$ & $\begin{array}{l}25.10 \% \pm \\
3.30 \%\end{array}$ & 0.0006 \\
\hline & & & & & & $\star \star \star$ & & \\
\hline \multirow[t]{2}{*}{$\begin{array}{l}\text { high } \mathrm{K}^{+} \\
\text {solution }\end{array}$} & 7 & a nonspecific depolarizing agent & 0 & $3 \times 10^{-2}$ & $\begin{array}{l}42.42 \% \pm \\
4.4 \%\end{array}$ & $\begin{array}{l}5.46 \% \pm \\
1.36 \%\end{array}$ & $\begin{array}{l}87.85 \% \pm \\
2.10 \%\end{array}$ & $<.0001$ \\
\hline & & & & & & $\star \star \star \star ~$ & & \\
\hline \multirow[t]{2}{*}{ TEA } & 7 & a nonspecific $\mathrm{K}^{+}$channel blocker & 30 & $10^{-2}$ & $\begin{array}{l}36.45 \% \pm \\
2.69 \%\end{array}$ & $\begin{array}{l}18.77 \% \pm \\
1.93 \%\end{array}$ & $\begin{array}{l}48.45 \% \pm \\
3.67 \%\end{array}$ & $<.0001$ \\
\hline & & & & & & 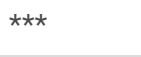 & & \\
\hline Glibenclamide, & 7 & an $\mathrm{K}_{\text {ATP }}$ blocker & 30 & $10^{-6}$ & $\begin{array}{l}41.32 \% \pm \\
2.72 \%\end{array}$ & $\begin{array}{l}54.97 \% \pm \\
4.27 \%\end{array}$ & $\begin{array}{l}-33.23 \% \pm \\
6.02 \%\end{array}$ & 0.0018 \\
\hline \multicolumn{9}{|c|}{ Effects of Extracellular $\mathrm{Ca}^{2+}$ and L-type VOCC Blocker } \\
\hline \multirow[t]{5}{*}{$\begin{array}{l}\text { Extracellular } \\
\mathrm{Ca}^{2+}\end{array}$} & 7 & & 25 & $1.25 \times 10^{-3}$ & $\begin{array}{l}48.13 \% \pm \\
5.23 \%\end{array}$ & $\begin{array}{l}38.02 \% \pm \\
4.50 \%\end{array}$ & $\begin{array}{l}21.35 \% \pm \\
3.19 \%\end{array}$ & 0.0728 \\
\hline & 7 & & 25 & $0.625 \times 10^{-3}$ & & $\begin{array}{l}28.02 \% \pm \\
4.00 \%\end{array}$ & $\begin{array}{l}42.16 \% \pm \\
3.90 \%\end{array}$ & 0.0175 \\
\hline & & & & & & * & & \\
\hline & 7 & & 25 & 0 & & $\begin{array}{l}17.04 \% \pm \\
3.32 \%\end{array}$ & $\begin{array}{l}64.62 \% \pm \\
6.03 \%\end{array}$ & 0.0070 \\
\hline & & & & & & ** & & \\
\hline Verapamil & 7 & an L-type VOCC blocker & 30 & $10^{-6}$ & $\begin{array}{l}40.09 \% \pm \\
3.55 \%\end{array}$ & $\begin{array}{l}47.97 \% \pm \\
4.56 \%\end{array}$ & $\begin{array}{l}-19.34 \% \pm \\
3.26 \%\end{array}$ & 0.0026 \\
\hline
\end{tabular}




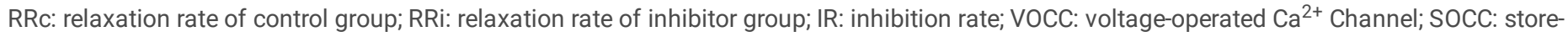
operated $\mathrm{Ca}^{2+}$ channel; MEGJ: myoendothelial gap junctions. ${ }^{* \star *} \mathrm{P}<0.001 ;{ }^{*} \mathrm{p}<0.01 ;{ }^{\star} \mathrm{p}<0.05$

Roles of the Nitric Oxide Synthase-nitric Oxide-soluble Guanylyl Cyclase (NOS-NO-sGC-Cgmp) Signalling Pathway, Products of Cyclooxygenase and EDH in Motilin-induced Vasorelaxation of LGA

L-NAME (a NOS inhibitor) and ODQ (a sGC inhibitor) markedly attenuated the motilin-induced vasorelaxation of LGA. Indomethacin, a cyclooxygenase inhibitor, slightly but significantly decreased motilin-induced relaxation. MEGJs and potassium channels [29] are two important factors that determine $\mathrm{EDH}$. Pre-treatment of LGA rings with 18a-GA, a MEGJ inhibitor, showed a partial attenuation of motilin-induced vasorelaxation. The high $\mathrm{K}^{+}$solution containing $3 \times 10^{-2} \mathrm{M} \mathrm{KCl}$, a nonspecific depolarising agent, markedly decreased the relaxation. TEA (a nonspecific $\mathrm{K}^{+}$channel blocker) partially attenuated the motilin-induced vasorelaxation. Glibenclamide, an ATP-sensitive $\mathrm{K}^{+}$channel $\left(\mathrm{K}_{\mathrm{ATP}}\right)$ blocker, increased the relaxation rate. The results are shown in Table 2, and representative original images are shown in Fig. 6.

The levels of NO and cGMP in LGA tissues (each $\mathrm{N}=3$ ) were tested. As shown in Fig. 7a, the basic level of NO in the LGA tissues incubated with $\mathrm{U} 46619\left(5 \times 10^{-8} \mathrm{M}\right)$ was only $2.454 \pm 0.40 \mu \mathrm{mol} \mathrm{g} \mathrm{g}^{-1}$ protein. acetylcholine $\left(10^{-5} \mathrm{M}\right)$ increased the NO level to 2.4 times that of the basal level, which was the highest in each group, and motilin $\left(9 \times 10^{-8} \mathrm{M}\right)$ increased the NO level to 1.3 times. GM109 $\left(10^{-5} \mathrm{M}\right)$ and L-NAME $\left(10^{-4} \mathrm{M}\right)$ significantly lowered NO production to less than that of basal NO; however, $\mathrm{H} 89\left(5 \times 10^{-6} \mathrm{M}\right)$ and chelerythrine $\left(2 \times 10^{-6} \mathrm{M}\right)$ significantly promoted NO production.

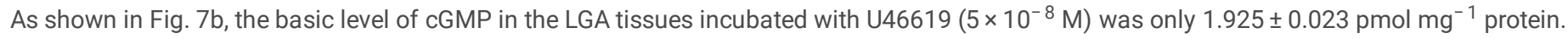
acetylcholine $\left(10^{-5} \mathrm{M}\right)$ increased the cGMP level to 2.5 times that of the basal level, and motilin $\left(9 \times 10^{-8} \mathrm{M}\right)$ increased the cGMP level to 1.5 times. GM-109 $\left(10^{-5} \mathrm{M}\right), \mathrm{L}-\mathrm{NAME}\left(10^{-4} \mathrm{M}\right)$ and ODQ $\left(10^{-5} \mathrm{M}\right)$ significantly inhibited the cGMP production, reducing it lower than that of basal cGMP. H89 $(5$ $\left.\times 10^{-6} \mathrm{M}\right)$ and chelerythrine $\left(2 \times 10^{-6} \mathrm{M}\right)$ promoted cGMP production.

\section{Effects of Extracellular $\mathrm{Ca}^{2+}$ and L-type Voltage-operated $\mathrm{Ca}^{2+}$ Channel Blocker on Motilin-induced Vasorelaxation of LGA}

The LGA rings were incubated in Krebs solutions with $\mathrm{Ca}^{2+}$ at 2.5 (control group), 1.25, 0.625 or 0 mM, respectively. The inhibitory effect on motilininduced relaxation was enhanced with decreased $\mathrm{Ca}^{2+}$ concentration.Compared with the control group, $\mathrm{Ca}^{2+}$ at $0.625 \times 10^{-3}$ and $0 \mathrm{M}^{2}$ were significantly different.

Verapamil, an L-type voltage-operated $\mathrm{Ca}^{2+}$ channel (VOCC) blocker, had no inhibitory effect on motilin-induced vasorelaxation.The results are depicted in Table 2, and the representative images are shown in Fig. 8.

\section{Discussion}

In this study, we not only demonstrated that MLNRs were expressed on membranes of endothelial cells of canine LGA but also revealed that motilin functioned primarily through the motilin-MLNR- G pr-PLC-IP $3-\mathrm{Ca}^{2+}-\mathrm{NOS}-\mathrm{NO}-\mathrm{sGC}-\mathrm{cGMP}$ signalling pathway to relax LGA. In addition, $\mathrm{PGI} \mathrm{I}_{2}$, EDHF and extracellular $\mathrm{Ca}^{2+}$ had roles. The signalling pathways of MLNR in inducing the relaxation of LGA is summarised in the model diagram (Fig. 9).

MLNRs were identified to express on the endothelial cell membrane of LGA in dogs by our immune and endothelial denudation experiments, which is a site that had only been speculated previously [12]. Motilin induced increased gastric blood flow [12] or LGA relaxation are both dose depended. We also demonstrated that GM-109 was the selective and competitive antagonist of endothelial MLNRs. The results that the antagonism parameter (pA2) of GM-109 for motilin (7.638) in LGA preparations was close to that demonstrated in the rabbit duodenum (7.37) [34] suggest that GM-109 has similar antagonistic activity on the MLNRs in the both sites, which is indicating that these MLNRs may have similar binding sites and/or features. We can conclude that MLNRs are no doubt the basic molecular structures required for motilin's effects on gastric arteries both in vivo [12] and in vitro experiments. Thus, there signal transduction pathway after MLNR in LGA must be the same.

Motilin plays a synergic and efficient role in regulating multiple physiological activities in the gastrointestinal tract. Although these effects are all MLNR and $\mathrm{G}$ pr depended, the following mechanism are quite different. In human and dogs, motilin's effects on gastrointestinal smooth muscles contraction $[26,27,35,36]$, hunger sensations and feeding signals [37] are all cholinergically facilitated and acetylcholine is thought to be the final mediator. However, the activated motilin-MLNR-G pr-PLC-IP 3 signal transduction pathway in in endothelial cells is much more directly. It is not related to acetylcholine, as its effect can't be inhibited by anticholinergic agents. It directly induced the release of vasorelaxing substances in endothelial cells. The NOS-NO-sGC-cGMP pathway plays a critical role in motilin-induced relaxation of canine LGA. We proved that NO is promoted only by motilin and released from vascular endothelial cells, but not from the intestinal neurons promoted by acetylcholine [35, 36] or motilin [20]. In addition to NO system, prostaglandins (mainly $\mathrm{PGI}_{2}$ ) and EDHF also play roles. However, the efficacies of the inhibitors (although in a high concentration) of the two pathways were relatively low, indicating that $\mathrm{PGI}_{2}$ and $\mathrm{EDHF}$ may not be the primary vasodilators in motilin-induced relaxation of canine $\mathrm{LGA}$.

In fact, the increase of the intracellular $\mathrm{Ca}^{2+}$ is related to. the production and release of all three vasorelaxing substances Motilin induced a two-phase increase in $\mathrm{Ca}^{2+}$ in endothelial cells of the porcine aortic valves: the initial increase is related to the release of $\mathrm{Ca}^{2+}$ from intracellular $\mathrm{Ca}^{2+}$ storage, $^{2}$ 
whereas the maintenance of a stable $\mathrm{Ca}^{2+}$ concentration was associated with extracellular $\mathrm{Ca}^{2+}$ inflow [24]. The release of Ca ${ }^{2+}$ from intracellular Ca ${ }^{2+}$ storage can be explained by the well-known G pr-PLC-IP3 signalling pathway. However, the inflow of extracellular Ca ${ }^{2+}$ was found to be related to the extracellular $\mathrm{Ca}^{2+}$ concentration and SOCC, and the effects of VOCC were excluded. This mechanism is very different from that in smooth muscle cells (excitable cells) [38], because endothelial cells are non-excitable cells and the resting potential may induce failure of $>50 \%$ of VocC activation [39].

Considering patients with diabetic gastroparesis always lost gastric phase III activities [3], MLNR agonists are often the candidate drugs for improving delayed gastric emptying or mimicking gastric MMC III in the treatment of diabetic gastroparesis [40, 41]. However, diabetic microangiopathy pathologically consists of damaged endothelial cells and capillary basement membrane thickening, in which endothelial dysfunction mainly manifests as the reduced production or release of NO [42]. It is just the main MLNR's signal transduction pathway inducing LGA relaxation discovered by us. This suggests a link between decreased ability of motilin to regulate gastric blood supply and the occurrence of diabetic gastroparesis. Furthermore, lack of a fundamental improvement in blood supply of gastric wall will no doubt contradict the effectiveness of motilin agonists. Thus, more measures related to protect the endothelial functions or improve the gastric blood should be taken account. Further research is warranted in a transgenic or geneknockout animal model of diabetic gastroparesis to characterise the more pathological roles of motilin and MLNRs in endothelial cells.

\section{Conclusions}

Conclusively, we provide the first evidence for the MLNR expression on membranes of endothelial cells of canine LGA. During motilin-induced relaxation, the motilin-MLNR-G pr-PLC-IP 3 signal transduction pathway was activated in endothelial cells. The NOS-NO-sGC-cGMP signal pathway was the major mechanism underlying smooth muscle cell relaxation. These results clearly demonstrated the signal transduction mechanism that motilin regulates gastric blood flow in dogs in the inter-digestive phase under physiological conditions and may provide a new theoretical basis for the research on diabetic gastroparesis.

\section{Abbreviations}

AC: Adenylate cyclase; EDH:Endothelium-dependent Hyperpolarization;GM-109:Phe-cyclo[Lys-Tyr(3-tBu)-Ala-]•trifluoroacetate; GPCR:G protein coupled receptor; H89:(N-2-[p-bromocinnamylamino]ethyl)-5-isoquinolinesulfonamidehydrochloride; IR:Inhibition rate; LGA:Left gastric artery; MLNR:Motilin receptor; MMC:Migrating motor complex; MR:Muscarinic Receptor; NEM:N-ethylmaleimide; NO:Nitric oxide; NOS:Nitric oxide synthase; ODQ:1H[1,2,4]oxadiazolo[4,3-a]quinoxalin-1-one; PKA:Protein kinase A; PKC:Protein kinase C; RR:Relaxation rate; sGC:Soluble guanylyl cyclase; SEM:Standard error of the mean; SOCC:Store-operated Ca2 + channel; TEA:Tetraethylammonium; VOCC:Voltage-operated Ca2 + channel; 2-APB:2-aminoethyl diphenylborinate; 18a-GA:18a-glycyrrhetinic acids.

\section{Declarations}

\section{Ethics approval and consent to participate}

All animal experiments were performed in accordance with approved animal protocols and guidelines established by the Institutional Animal Care and Use Committee of Jilin University (Number of permit: 2016301) and conducted according to the recommendations of the Guide for the Care and Use of Laboratory Animals of the National Institutes of Health.

\section{Consent for publication}

Not applicable

\section{Availability of data and materials}

The datasets used and/or analysed during the current study are available from the corresponding author on reasonable request.

\section{Competing interests}

The authors declare that they have no competing interests.

\section{Funding}

This work was supported by grants from the National Natural Science Foundation of China (Grant No. 31271235 to C.J.) and the Science and Technology Department of Jilin Province (Grant No. 20170414042GH to C.J.).

\section{Authors' contributions}

Chunxiang Jin: Conception; Hongyu Li and Lanlan Yang: Data collection; Hongyu Li and Lanlan Yang: Data analysis; Hongyu Li: drafting of the manuscript; Hongyu Li, Chunxiang Jin and Ying Jin: revision of the manuscript. All authors read and approved the final manuscript 
We thank RaQualia Pharma, Inc., Taketoyo, Japan for kindly providing the rabbit anti-dog MLNR antibody.

Data availability statement

The main data used to support the findings of this study are included within the article.

Author details

${ }^{1}$ Department of Ultrasound, China-Japan Union Hospital of Jilin University, Changchun, Jilin, P.R. China

${ }^{2}$ Department of Ultrasound, the Second Department of the First Hospital of Jilin University, Changchun, Jilin, P. R. China

${ }^{3}$ Department of Hepatopancreatobiliary Medicine, the Second Hospital of Jilin University, Changchun, Jilin, P. R. China

${ }^{4}$ Department of Breast Surgery, the First Hospital of Jilin University, Changchun, Jilin, P. R. China

\section{References}

1. Suzuki S, Suzuki H, Horiguchi K, Tsugawa H, Matsuzaki J, Takagi T, Shimojima N, Hibi T: Delayed gastric emptying and disruption of the interstitial cells of Cajal network after gastric ischaemia and reperfusion. Neurogastroenterology and motility : the official journal of the European Gastrointestinal Motility Society 2010, 22(5):585-593, e126.

2. Shen HL, Yang SP, Wang KJ, Huang BL, Huang WB, Wu JZ, Lv GR: Evaluation of gastric blood supply in diabetic patients with gastroparesis by contrast-enhanced ultrasound. The British journal of radiology 2016, 89(1068):20160366.

3. Achem-Karam SR, Funakoshi A, Vinik Al, Owyang C: Plasma motilin concentration and interdigestive migrating motor complex in diabetic gastroparesis: effect of metoclopramide. Gastroenterology 1985, 88(2):492-499.

4. Marlett CFCaJA: The interdigestive myo-electric complex of the stomach and small bowel of dogs. J Physio/ 1975, 246:289-309.

5. Dooley CP, Di Lorenzo C, Valenzuela JE: Variability of migrating motor complex in humans. Digestive diseases and sciences 1992, 37(5):723-728.

6. Lee KY, Chang TM, Chey WY: Effect of rabbit antimotilin serum on myoelectric activity and plasma motilin concentration in fasting dog. Am $J$ Physiol 1983, 245(4):G547-553.

7. Poitras P: Motilin is a digestive hormone in the dog.Gastroenterology 1984, 87( 4 ):909-913.

8. E. Deloose RV, M . Corsetti , I . Depoortere, J. Tack: Endogenous motilin, but not ghrelin plasma levels fluctuate in accordance with gastr ic phase III activity of the migr ating motor complex in man. Ne urogastroe nte rology \& Motility 2015, 27(1):63-71.

9. Ozaki K, Onoma M, Muramatsu H, Sudo H, Yoshida S, Shiokawa R, Yogo K, Kamei K, Cynshi O, Kuromaru O et al: An orally active motilin receptor antagonist, MA-2029, inhibits motilin-induced gastrointestinal motility, increase in fundic tone, and diarrhea in conscious dogs without affecting gastric emptying. Eur J Pharmacol 2009, 615(1-3):185-192.

10. Polak JMP, A. G. Heath, C. M.: Complete identification of endocrine cells in the gastrointestinal tract using semithin-thin sections to identify motilin cells in human and animal intestine. Gut 1975, 16(3):225-229.

11. Itoh Z, Takeuchi S, Aizawa I, Mori K, Taminato T, Seino Y, Imura H, Yanaihara N: Changes in plasma motilin concentration and gastrointestinal contractile activity in conscious dogs. Digestive Diseases 1978, 23(10):929-935.

12. Jin C, Naruse S, Kitagawa M, Ishiguro H, Muxin W, Nakajima M, Yokohata K, Ito O, Hayakawa T: Motilin regulates interdigestive gastric blood flow in dogs. Gastroenterology 2002, 123(5):1578-1587.

13. Livingston EH, Howard TJ, Garrick TR, Passaro EP, Jr., Guth PH: Strong gastric contractions cause mucosal ischemia. Am J Physio/ 1991 , 260(3 Pt 1):G524-530.

14. He YW, H. Yang, D. Wang, C., Yang LJ, C.: Differential expression of motilin receptor in various parts of gastrointestinal tract in dogs. Gastroenterology research and practice 2015, 2015:970940.

15. Ohshiro HN, Miki Ichikawa, Katsuomi: Molecular identification and characterization of the dog motilin receptor. Regulatory Peptides 2008, 146(13):80-87.

16. Miller P, LT, SS-P, HT, PP: Neural and muscular receptors for motilin in the rabbit colon. Peptides 2000, 21:283-287.

17. Miller P, Roy A, St-Pierre S, Dagenais M, Lapointe R, Poitras P: Motilin receptors in the human antrum. American journal of physiology Gastrointestinal and liver physiology 2000, 278(1):G18-23.

18. Suzuki Al, Yuko Aizawa, Sayaka Sakata, Ichiro Tsutsui, Chihiro Mondal, Anupom Kanako, Koike Sakai, Takafumi: Molecular identification of GHS-R and GPR38 in Suncus murinus.Peptides 2012, 36(1):29-38.

19. Leen Thielemans ID, Gert Van Assche, Eckhard Bender ,Theo L. Peetersa Demonstration of a functional motilin receptor in TE671cells from human cerebel.Brain Research 2001, 895: 119-128.

20. Scott D. Feighner CPT, Karen Kulju McKee: Receptor for Motilin Identifed in the Human Gastrointestinal System. SCIENCE 1999, 284.

21. I. Depoortere TLP: Transduction mechanism of motilin and motilides in rabbit duodenal smooth muscle. Regulatory Peptides 1995, 55:227-235.

Page $10 / 27$ 
22. Jiean Huang HZ, Sunila Mahavadi, Wimolpak Sriwai, Vijay Lyall and Karnam S. Murthy: Signaling pathways mediating gastrointestinal smooth muscle contraction and MLC20phosphorylation by motilin receptors. Am J Physiol Gastrointest Liver Physiol 2005, 288:G23-G31.

23. Fang PD, L. Luo, J. Y.: Effects of motilin on intracellular free calcium in cultured smooth muscle cells from the antrum of neonatal rats. Acta physiologica 2010, 199(1):53-61.

24. Higuchi Y, Nushimura J, Kanaide H: Motilin Induces the Endothelium-Dependent Relaxation of Smooth Muscle and the Elevation of Cytosolic Calcium in Endothelial Cells in Situ. Biochemical and biophysical research communications 1994, 202:346-353.

25. Iwai T, Nakamura H, Takanashi H, Yogo K, Ozaki K, Ishizuka N, Asano T: Hypotensive mechanism of [Leu13]motilin in dogs in vivo and in vitro. Can J Physiol Pharmacol 1998, 76(12):1103-1109.

26. Akiyoshi Mizumoto IS, Yugo Matsunaga, Osamu Yamamoto, Zen Itoh, Kihachi Ohshima: Mechanism of motilin-induced contractions in isolated perfused canine stomach.GASTROENTEROLOGY1993, 105:425-443.

27. Inatomi N, Sato F, Marui S, Itoh Z, Omura S: Vagus-Dependent and Vagus-Independent Mechanisms of Action of the Erythromycin Derivative EM574 and Motilin in Dogs. The Japanese Journal of Pharmacology 1996, 71(1):29-38.

28. Robert F. Furchgoot JVZ: The obligatory role of endothelial cells in the relaxation of arterial smooth muscle by acetylcholine Nature 1980, 288:373376.

29. Michel Félétou P: Endothelium-Dependent Hyperpolarization and Endothelial Dysfunction. J Cardiovasc Pharmaco/ 2016, 67:373-387.

30. Sun D, Liu H, Yan C, Jacobson A, Ojaimi C, Huang A, Kaley G: COX-2 contributes to the maintenance of flow-induced dilation in arterioles of eNOSknockout mice. American journal of physiology Heart and circulatory physiology 2006, 291(3):H1429-1435.

31. Mitselos A, Depoortere I, Peeters TL: Delineation of the motilin domain involved in desensitization and internalization of the motilin receptor by using full and partial antagonists. Biochem Pharmacol 2007, 73(1):115-124.

32. Van Rossum JM: Cumulative dose-response curves. II. Technique for the making of dose-response curves in isolated organs and the evaluation of drug parameters. Arch Int Pharmacodyn Ther 1963, 143:299-330.

33. Schachter D: L-Glutamine in vitro regulates rat aortic glutamate content and modulates nitric oxide formation and contractility responses. Am $J$ Physiol Cell Physiol 2007, 293: C142-C151.

34. Hisanori Tankanashi Ky, Kenichi Ozaki, Makoto Ikuta, Michitaka Akima, Hiraoshi Koga and Hirovuki Nabata: GM-109 a novel, selective motilin receptor antagonist inthe smooth muscle of the rabbit small intestine. The Journal of pharmacology and experimental therapeutics 1995, 273:624628.

35. Broad J, Mukherjee S, Samadi M, Martin JE, Dukes GE, Sanger GJ: Regional- and agonist-dependent facilitation of human neurogastrointestinal functions by motilin receptor agonists. Br J Pharmacol 2012, 167(4):763-774.

36. Broad J, Goralczyk A, Mannur K, Dukes GE, Sanger GJ: Drugs acting at 5-HT4 , D2 , motilin, and ghrelin receptors differ markedly in how they affect neuromuscular functions in human isolated stomach. Neurogastroenterology and motility : the official journal of the European Gastrointestinal Motility Society 2014, 26(6):851-861.

37. Deloose E, Vos R, Janssen P, Van den Bergh O, Van Oudenhove L, Depoortere I, Tack J: The motilin receptor agonist erythromycin stimulates hunger and food intake through a cholinergic pathway. The American journal of clinical nutrition 2016, 103(3):730-737.

38. Guerrero-Hernandez A, Kato S, Takahashi A, Shindo M, Yoshida A, Kawamura T, Matsumoto K, Matsuura B: Characterization of the gastric motility response to human motilin and erythromycin in human motilin receptor-expressing transgenic mice. Plos One 2019, $14(2): \mathrm{e} 0205939$.

39. Droogmans BNaG: Ion channels and their functional role in vascular Eedothelium.Physiological Reviews 2001, 81(4):1415-1459.

40. Deloose E, Verbeure W, Depoortere I, Tack J: Motilin: from gastric motility stimulation to hunger signalling. Nature reviews Endocrinology 2019, 15(4):238-250.

41. Kumar M, Chapman A, Javed S, Alam U, Malik RA, Azmi S: The Investigation and Treatment of Diabetic Gastroparesis. Clinical therapeutics 2018, 40(6):850-861.

42. Zhang H, Liu J, Qu D, Wang L, Wong CM, Lau CW, Huang Y, Wang YF, Huang H, Xia Y et al: Serum exosomes mediate delivery of arginase 1 as a novel mechanism for endothelial dysfunction in diabetes. Proceedings of the National Academy of Sciences of the United States of America 2018 , 115(29):E6927-E6936.

\section{Figures}


a

(A)

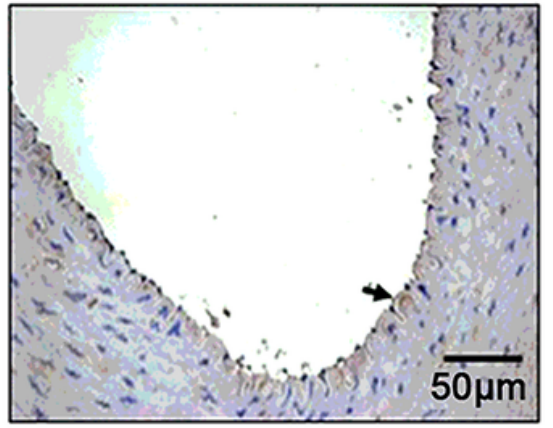

(B)

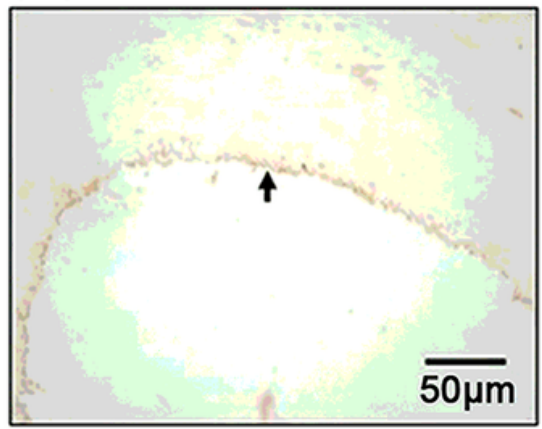

(C)

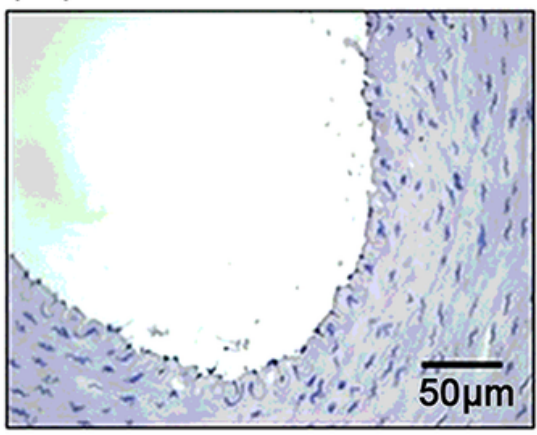

b

LGA

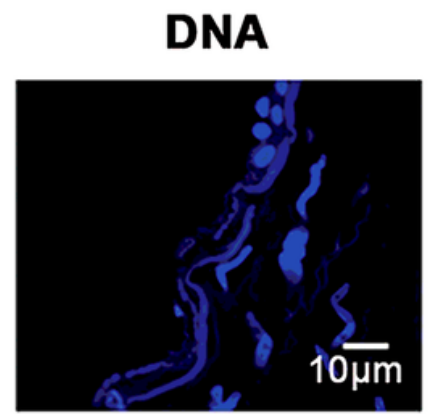

CD34

Motilin receptor

Merged
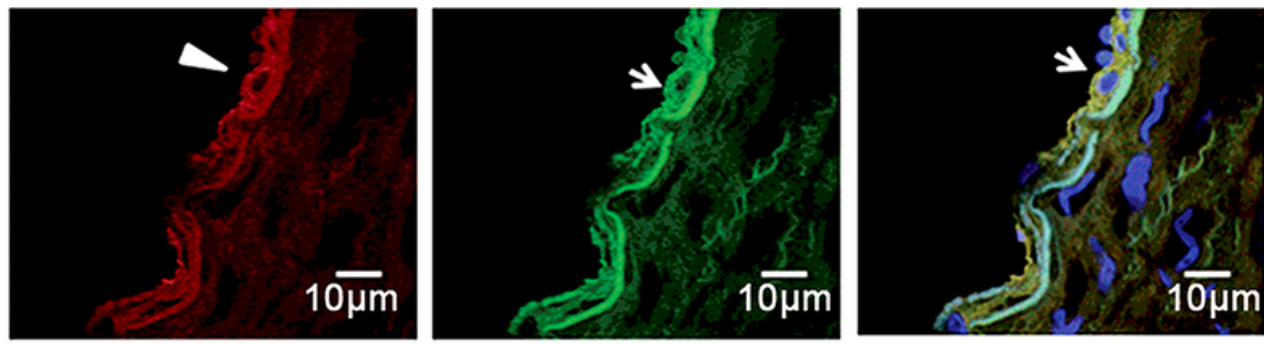

Control
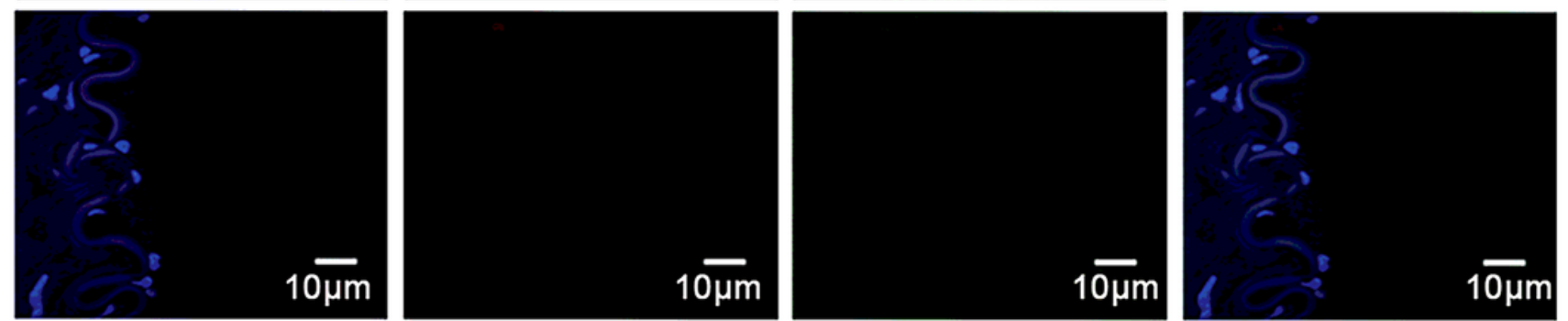

Figure 1

Immunostaining of MLNR on the LGA (a) Immunohistochemical staining of the MLNR: Brown line-like staining along the endothelium of the LGA (black arrows) (magnification, 400x; Scale bar, $50 \mu \mathrm{m}$ ). (A) MLNR detection with nuclei counterstaining. (B) MLNR detection without nuclei counterstaining. (C) Negative controls with nuclei counterstaining. (b) Immunofluorescence staining of the MLNR. Cellular localization of MLNR and CD34 expression were using an anti-MLNR antibody, FITC-labelled secondary antibody (green), anti-CD34 antibody and Cy3-labelled secondary antibody (red). The nuclei were stained with Hoechst 33342 (blue). On the membrane of the endothelium, CD34 expression (white arrowheads) and MLNR expression (white arrows) were detected. Scale bar, $10 \mu \mathrm{m}$. MLNR: motilin receptor; LGA: left gastric artery; FITC: fluorescein isothiocyanate 
a

(A)

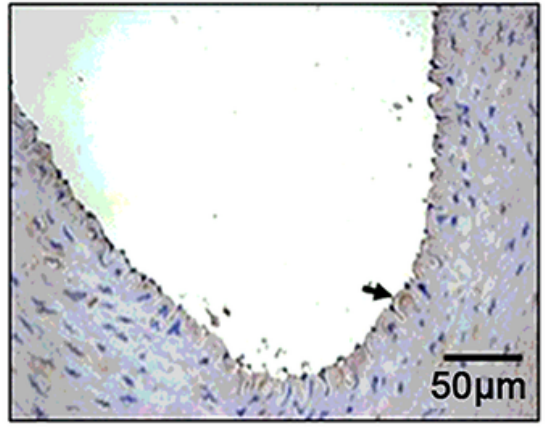

(B)

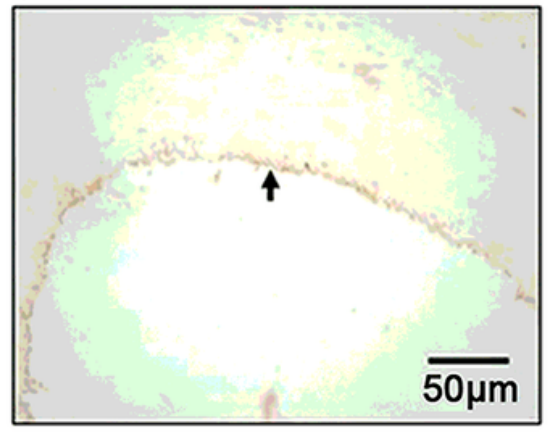

(C)

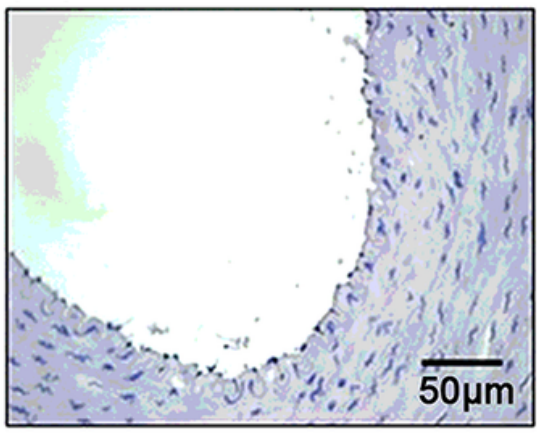

b

LGA

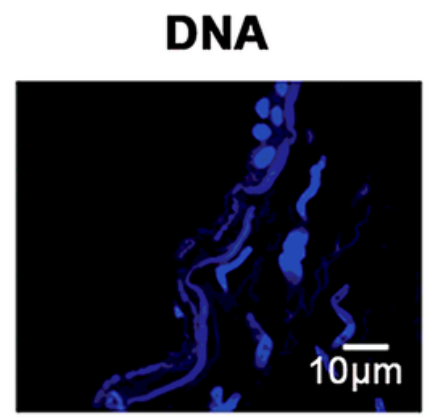

CD34

Motilin receptor

Merged
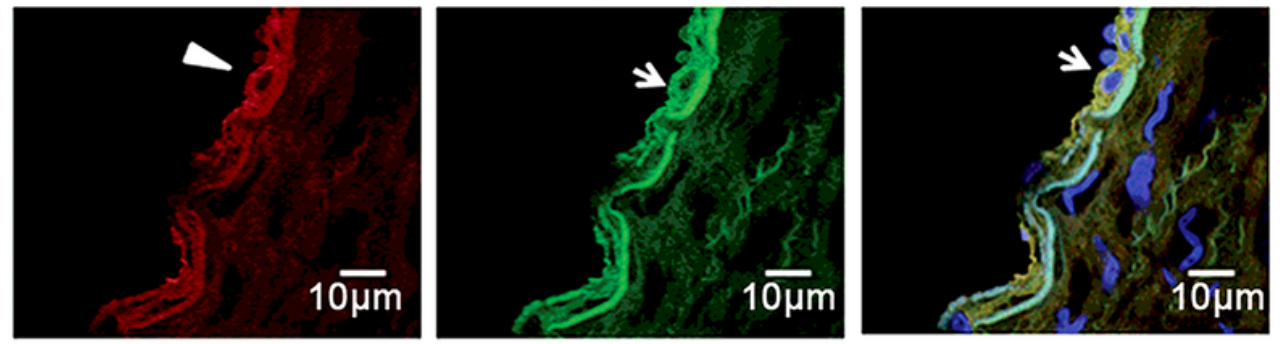

Control
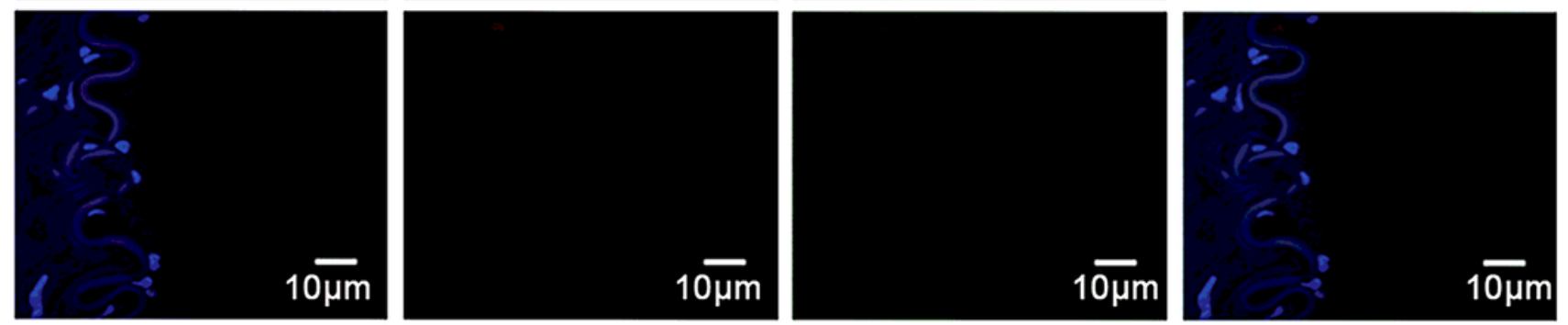

Figure 1

Immunostaining of MLNR on the LGA (a) Immunohistochemical staining of the MLNR: Brown line-like staining along the endothelium of the LGA (black arrows) (magnification, 400x; Scale bar, $50 \mu \mathrm{m}$ ). (A) MLNR detection with nuclei counterstaining. (B) MLNR detection without nuclei counterstaining. (C) Negative controls with nuclei counterstaining. (b) Immunofluorescence staining of the MLNR. Cellular localization of MLNR and CD34 expression were using an anti-MLNR antibody, FITC-labelled secondary antibody (green), anti-CD34 antibody and Cy3-labelled secondary antibody (red). The nuclei were stained with Hoechst 33342 (blue). On the membrane of the endothelium, CD34 expression (white arrowheads) and MLNR expression (white arrows) were detected. Scale bar, $10 \mu \mathrm{m}$. MLNR: motilin receptor; LGA: left gastric artery; FITC: fluorescein isothiocyanate 

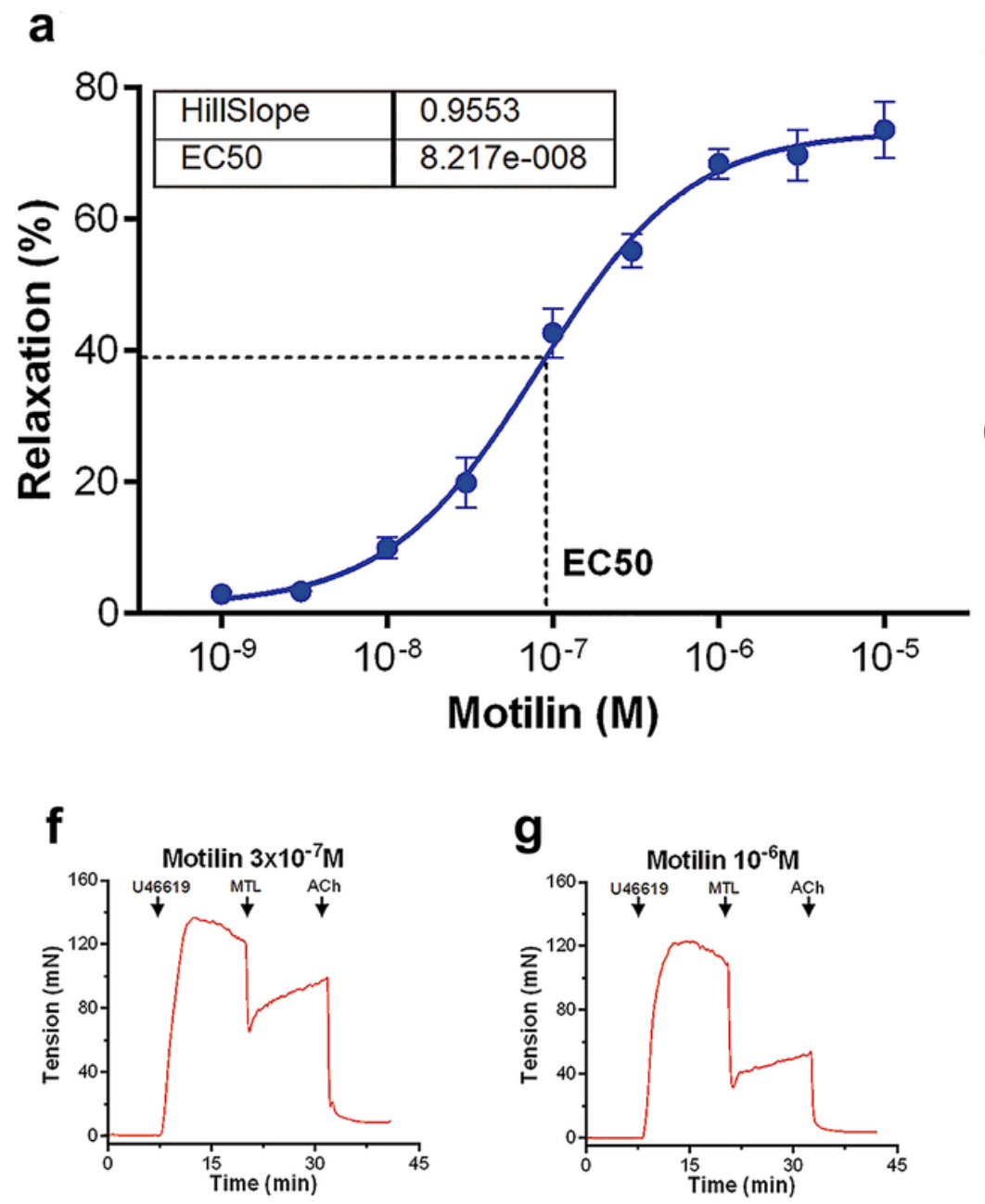

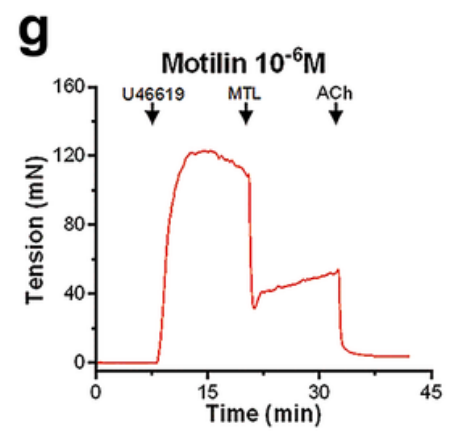

b
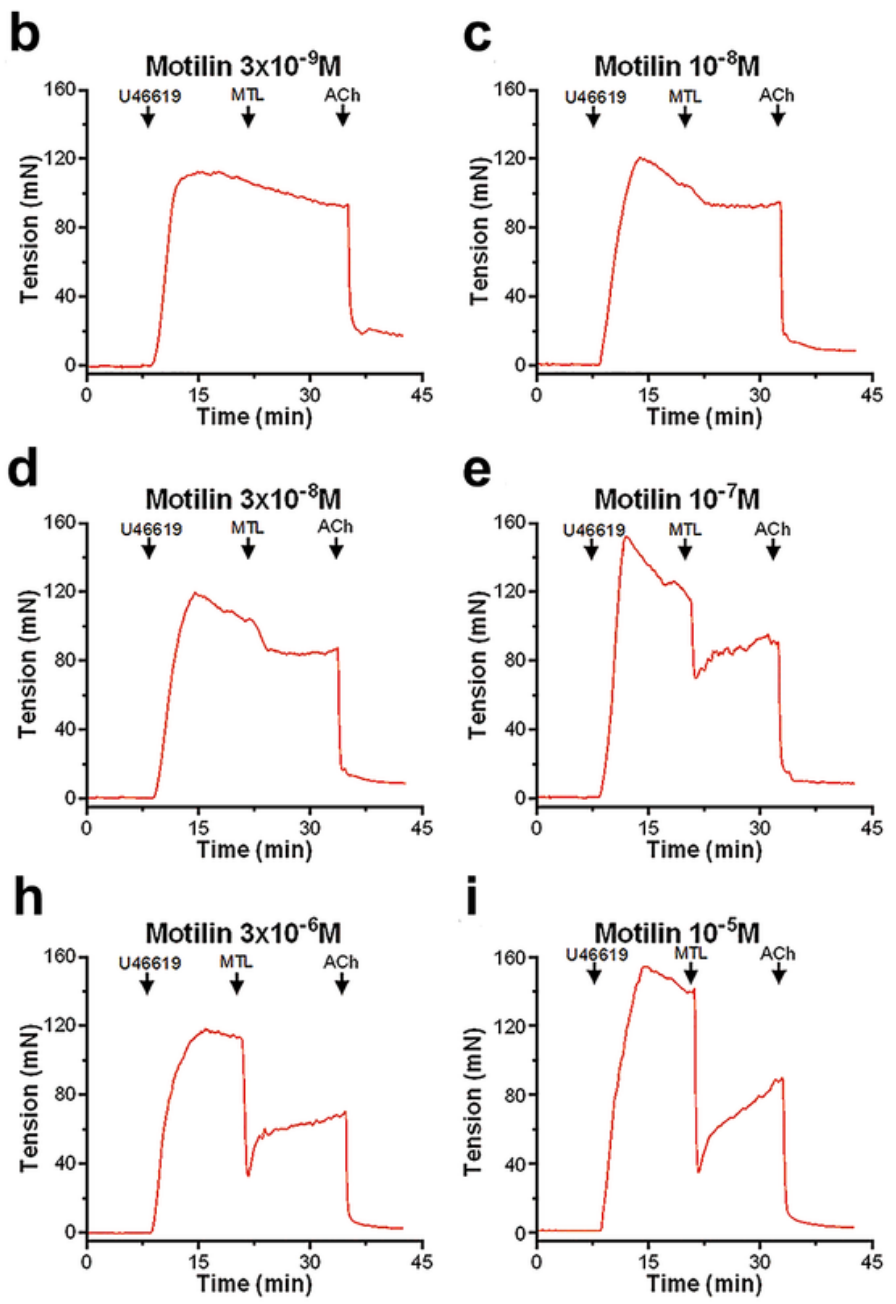

Figure 2

The relaxant effect of motilin on U46619 pre-contracted canine LGA rings (a) The concentration-response curve for motilin (10-9-10-5 M)-induced relaxation on U46619 ( $5 \times 10-8 \mathrm{M})$ pre-contracted canine LGA rings with EC50 and HillSlope values. Means \pm SEM are provided $(n=7)$. $(b-i)$ Representative original curves of motilin $(3 \times 10-9,10-8,3 \times 10-8,10-7,3 \times 10-7,10-6,3 \times 10-6$ and 10-5 M)-induced relaxation in U46619 (5 $\times$ 10-8 M) pre-contracted LGA, with acetylcholine-induced relaxation $(>80 \%)$ at the end of each test. Black arrow indicates the dosing point. MTL: motilin; ACh: acetylcholine; LGA: left gastric artery 

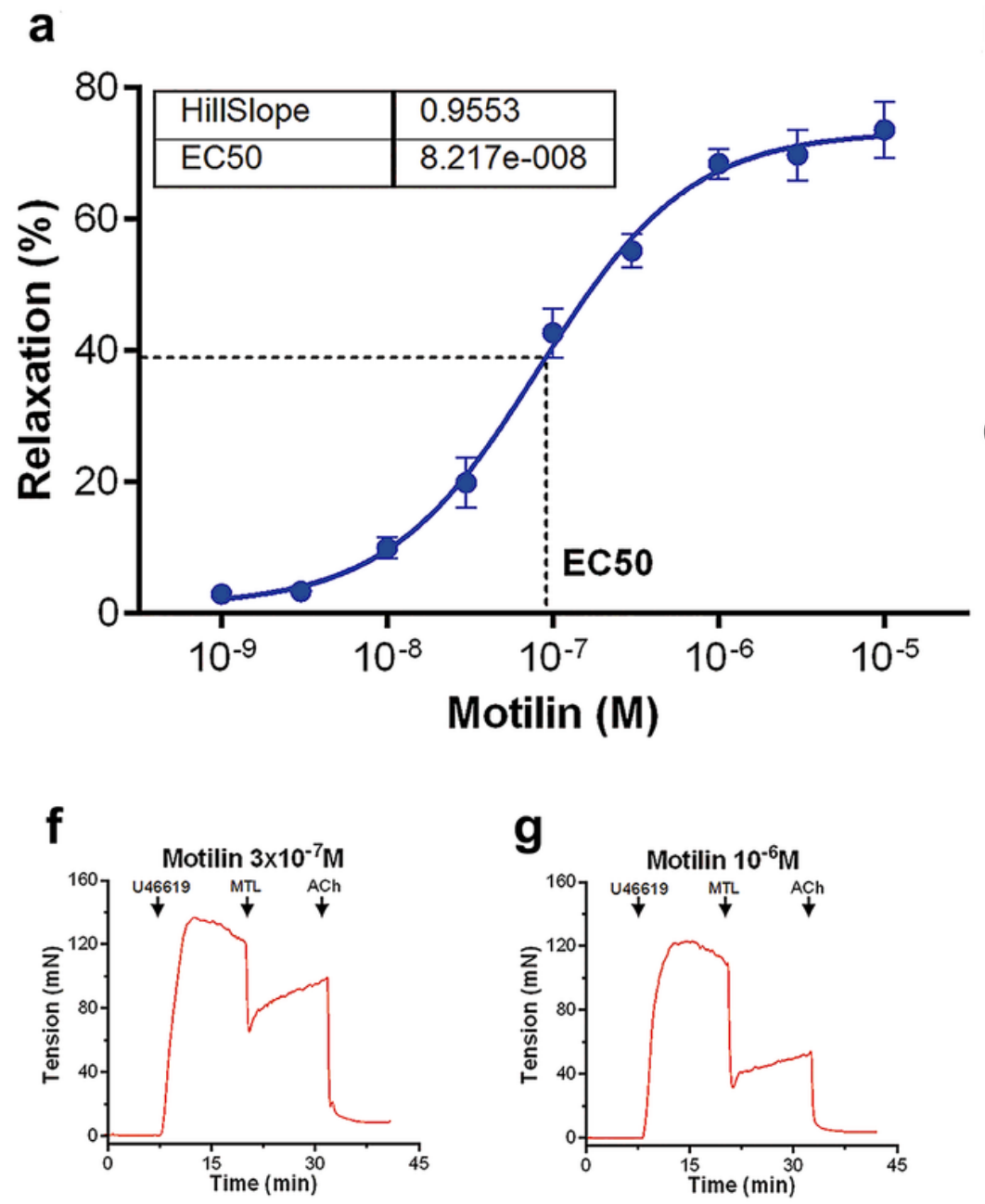

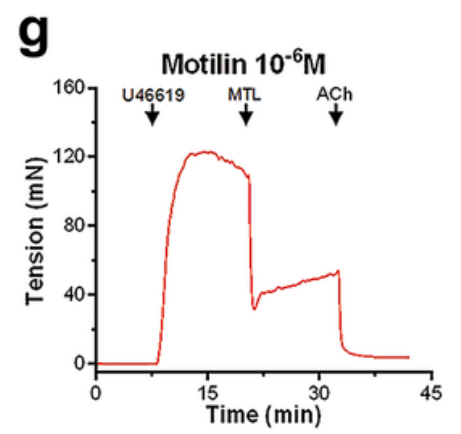

b
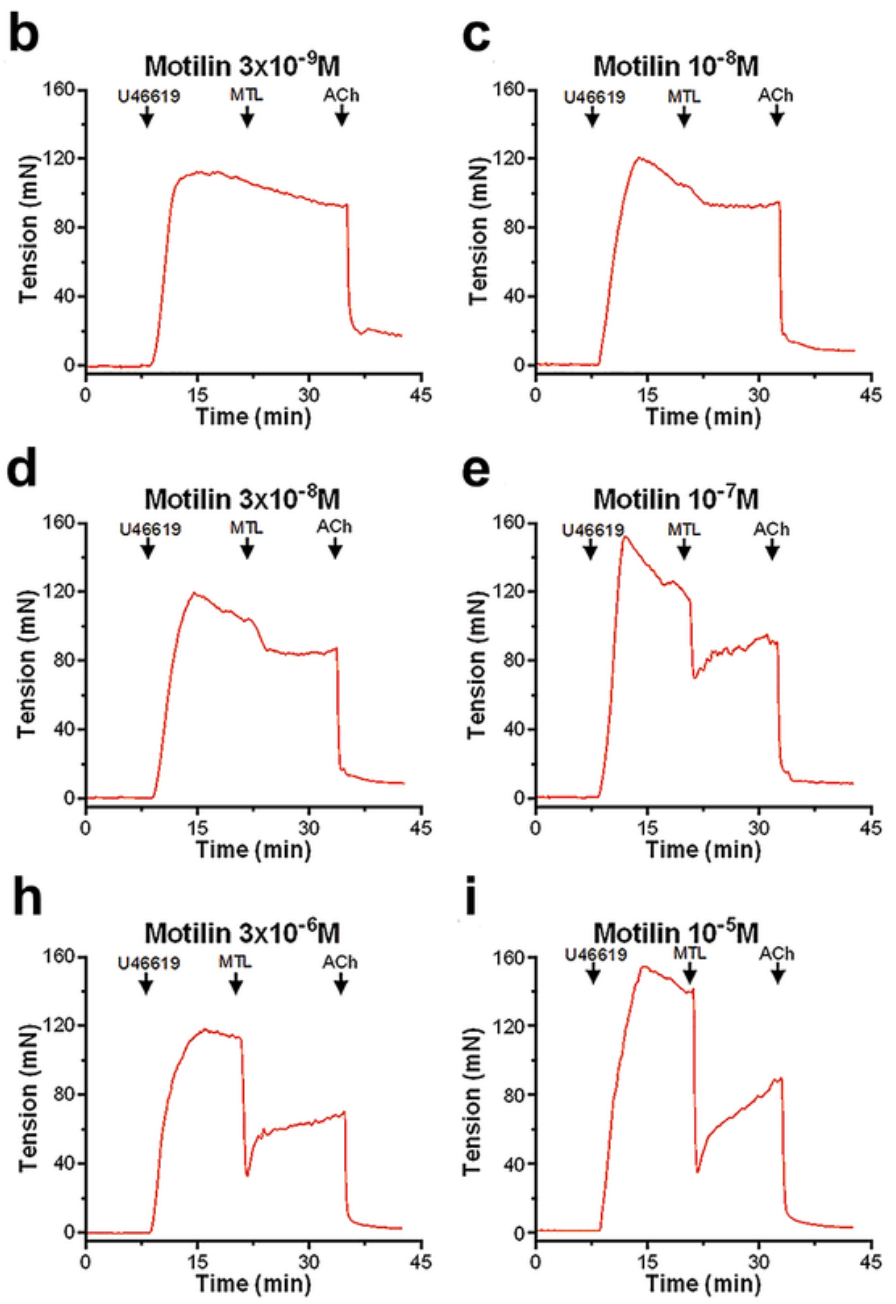

Figure 2

The relaxant effect of motilin on U46619 pre-contracted canine LGA rings (a) The concentration-response curve for motilin (10-9-10-5 M)-induced relaxation on U46619 ( $5 \times 10-8 \mathrm{M})$ pre-contracted canine LGA rings with EC50 and HillSlope values. Means \pm SEM are provided $(n=7)$. $(b-i)$ Representative original curves of motilin $(3 \times 10-9,10-8,3 \times 10-8,10-7,3 \times 10-7,10-6,3 \times 10-6$ and 10-5 M)-induced relaxation in U46619 (5 $\times$ 10-8 M) pre-contracted LGA, with acetylcholine-induced relaxation $(>80 \%)$ at the end of each test. Black arrow indicates the dosing point. MTL: motilin; ACh: acetylcholine; LGA: left gastric artery 


\section{E- or ATRO}

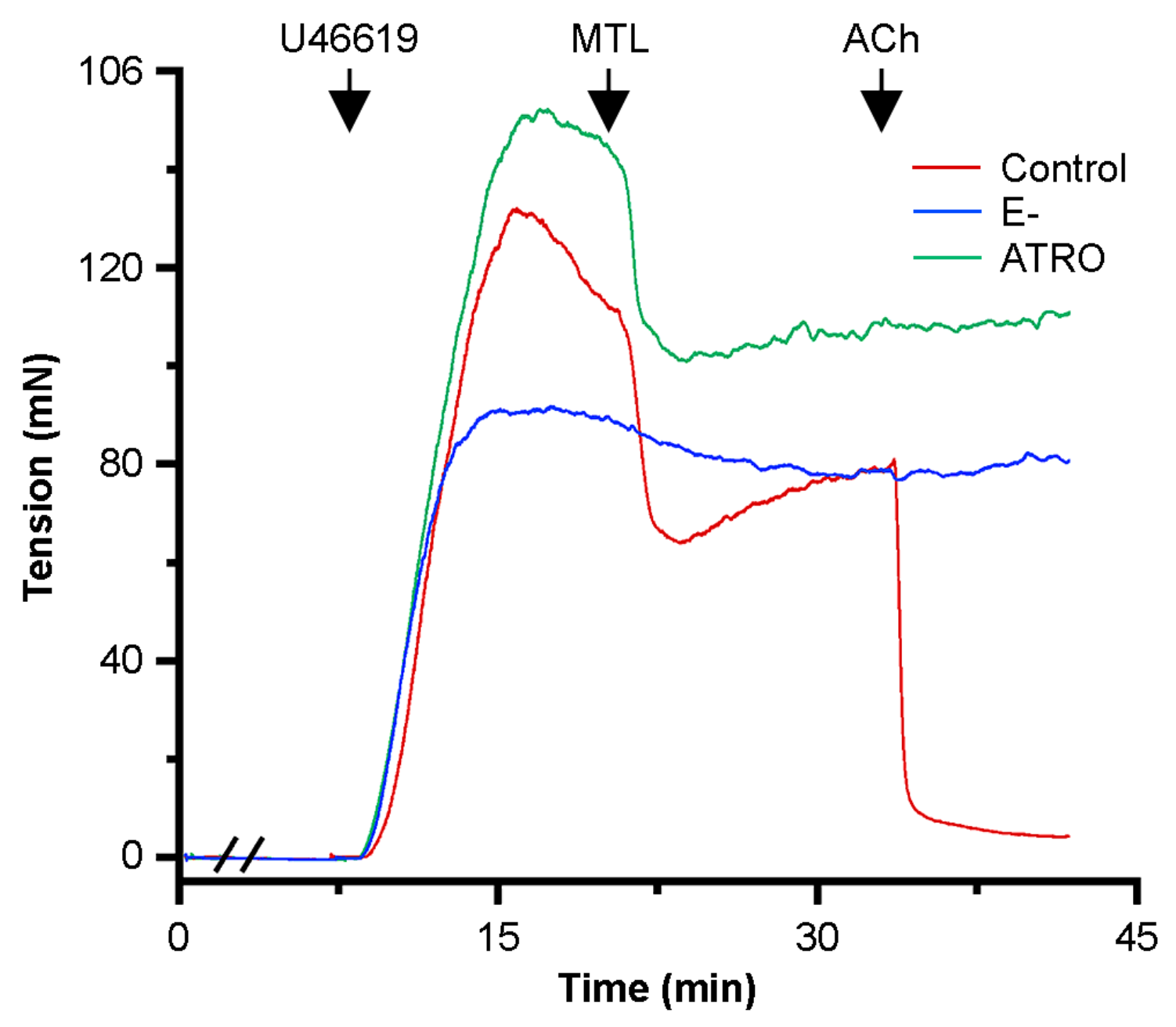

Figure 3

The original traces of motilin-induced relaxation of LGA rings pre-treated by endothelium denudation or atropine With endothelium (blue) or atropine (10-5 M) (green) or without (red), the double slash (//) indicates that the blocking process was prior to the addition of U46619. MTL: motilin; ACh: acetylcholine; E: endothelium-denudation; LGA: left gastric artery 


\section{E- or ATRO}

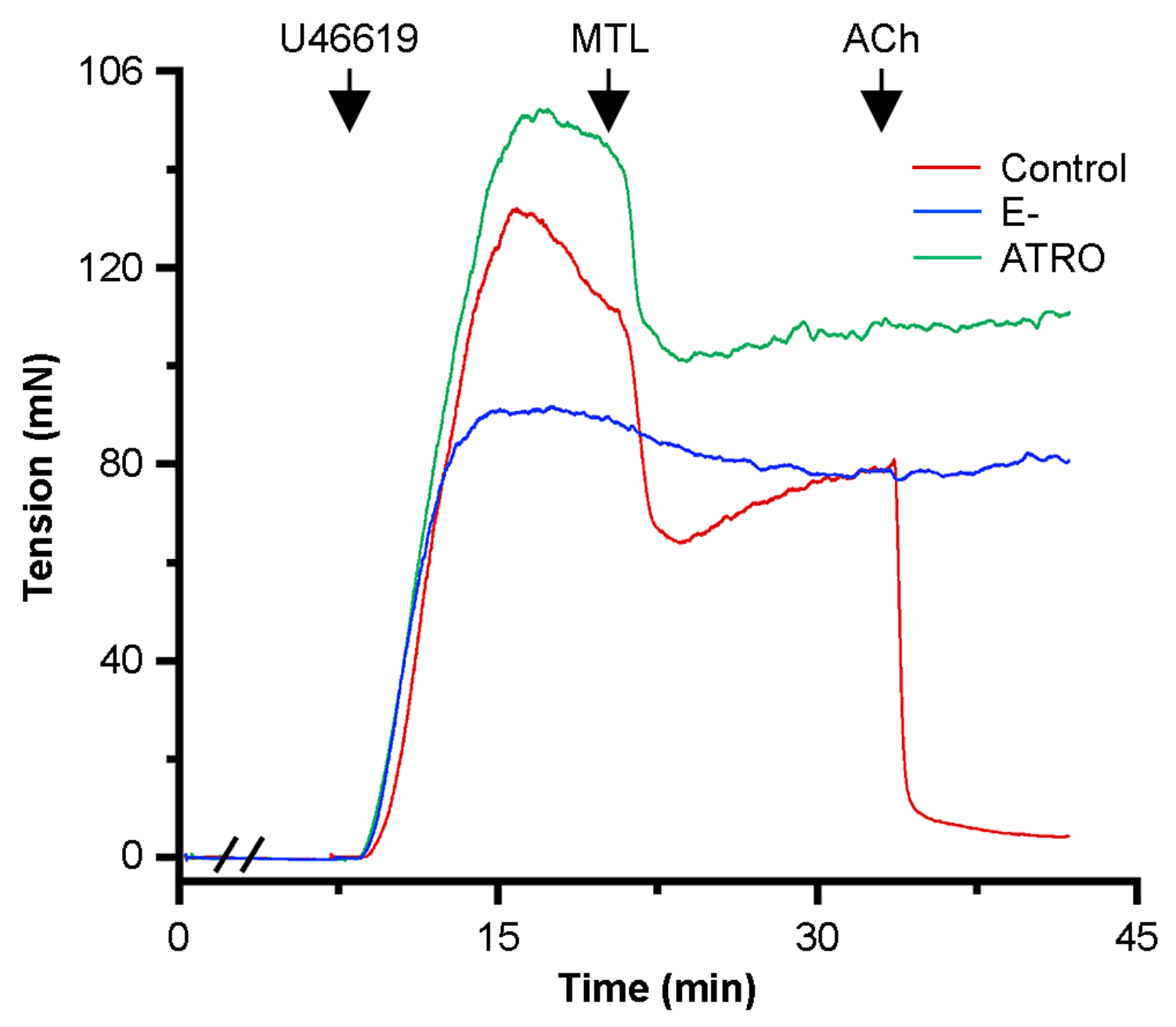

Figure 3

The original traces of motilin-induced relaxation of LGA rings pre-treated by endothelium denudation or atropine With endothelium (blue) or atropine (10-5 M) (green) or without (red), the double slash (//) indicates that the blocking process was prior to the addition of U46619. MTL: motilin; ACh: acetylcholine; E: endothelium-denudation; LGA: left gastric artery 
a

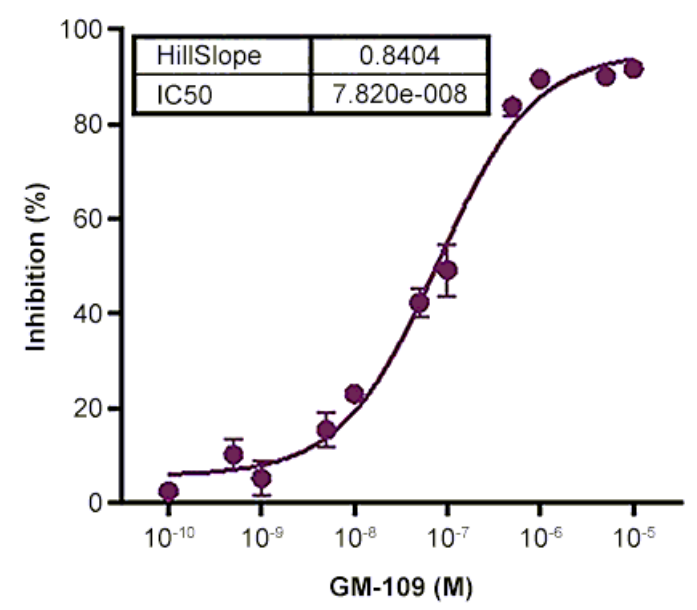

C

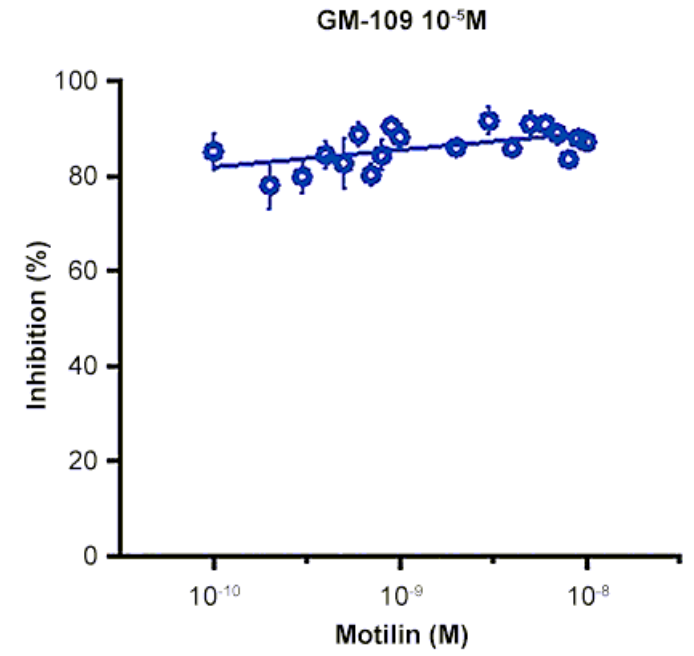

b

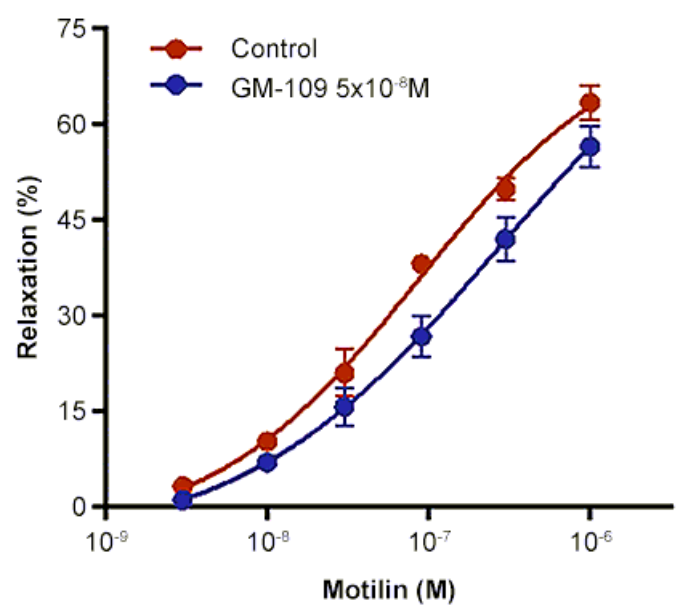

d

GM-109 $10^{-5} \mathrm{M}$ and/or Vehicle

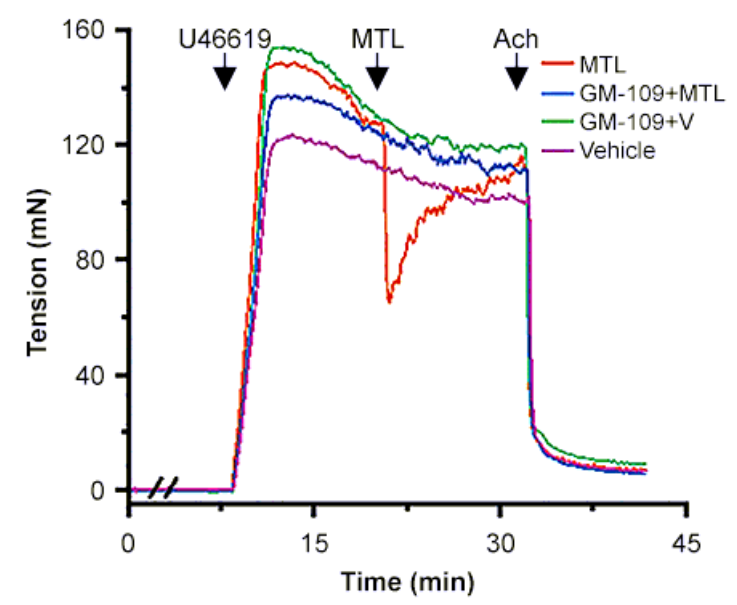

Figure 4

The effect of GM-109 on motilin-induced vasorelaxation in canine LGA rings (a) The concentration-dependent inhibitory effect of GM-109 (10-1010-5 M) on MTL ( $9 \times 10-8$ M)-induced relaxation $(n=7)$, with IC50 and HillSlope values. (b) GM-109 $(5 \times 10-8 \mathrm{M})$ shifts the concentration-response curve of motilin (10-8-10-6 M) to right $(n=5)$. (c) Scatter plots of the inhibitory effect of GM-109 (10-5 M) on motilin (10-8-10-6 M)-induced vasorelaxation $(n=5)$. In Fig. 4c, Means \pm SEM are given. (d) The original traces of vessels induced by motilin and/or GM-109 in U46619 precontracted LGA rings from one dog. Motilin $(9 \times 10-8 \mathrm{M})$ only (red), pre-incubated with GM-109 (10-5 M) and motilin $(9 \times 10-8 \mathrm{M})$ (blue), pre-treatment with GM-109 (10-5 M) only (green) and vehicle instead of GM-109 and motilin (purple). At the end of each test, acetylcholine was added. The double slash (//) indicates that the blocking process was prior to the addition of U46619. MTL: motilin; ACh: acetylcholine; V:vehicle; LGA: left gastric artery 
a

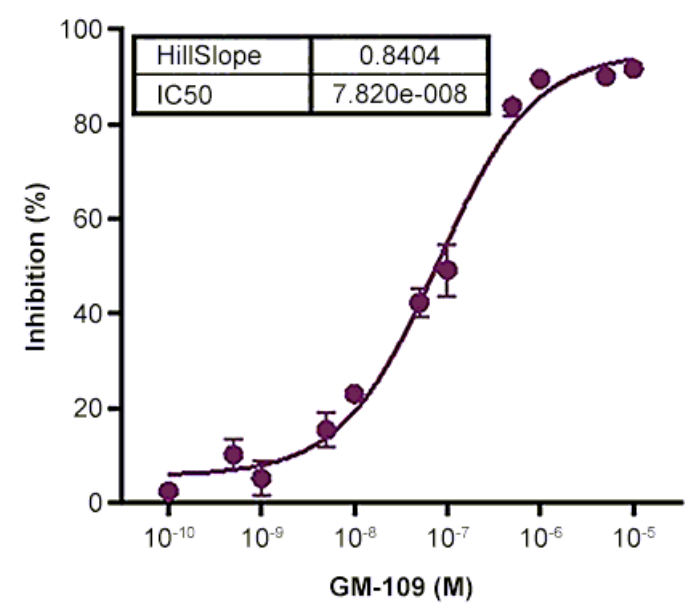

C

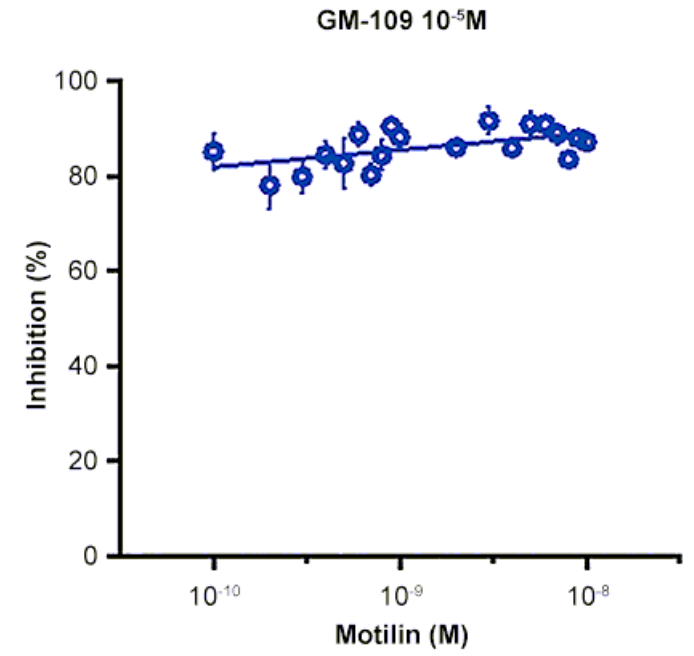

b

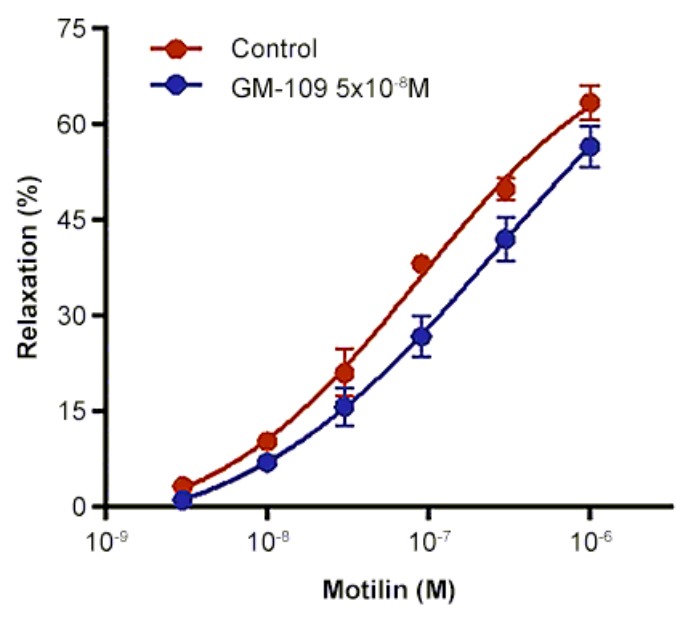

d

GM-109 $10^{-5} \mathrm{M}$ and/or Vehicle

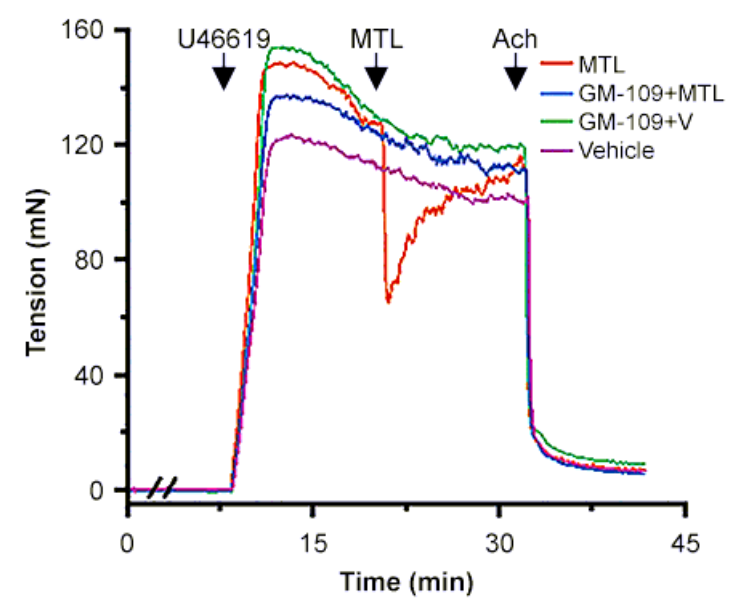

Figure 4

The effect of GM-109 on motilin-induced vasorelaxation in canine LGA rings (a) The concentration-dependent inhibitory effect of GM-109 (10-1010-5 M) on MTL ( $9 \times 10-8$ M)-induced relaxation $(n=7)$, with IC50 and HillSlope values. (b) GM-109 $(5 \times 10-8 \mathrm{M})$ shifts the concentration-response curve of motilin (10-8-10-6 M) to right $(n=5)$. (c) Scatter plots of the inhibitory effect of GM-109 (10-5 M) on motilin (10-8-10-6 M)-induced vasorelaxation $(n=5)$. In Fig. 4c, Means \pm SEM are given. (d) The original traces of vessels induced by motilin and/or GM-109 in U46619 precontracted LGA rings from one dog. Motilin $(9 \times 10-8 \mathrm{M})$ only (red), pre-incubated with GM-109 (10-5 M) and motilin $(9 \times 10-8 \mathrm{M})$ (blue), pre-treatment with GM-109 (10-5 M) only (green) and vehicle instead of GM-109 and motilin (purple). At the end of each test, acetylcholine was added. The double slash (//) indicates that the blocking process was prior to the addition of U46619. MTL: motilin; ACh: acetylcholine; V:vehicle; LGA: left gastric artery 
a

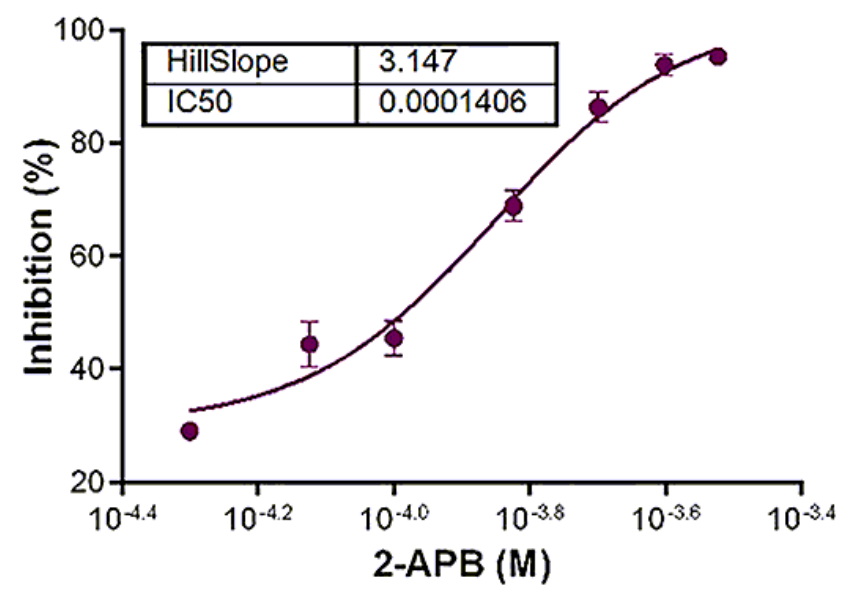

C

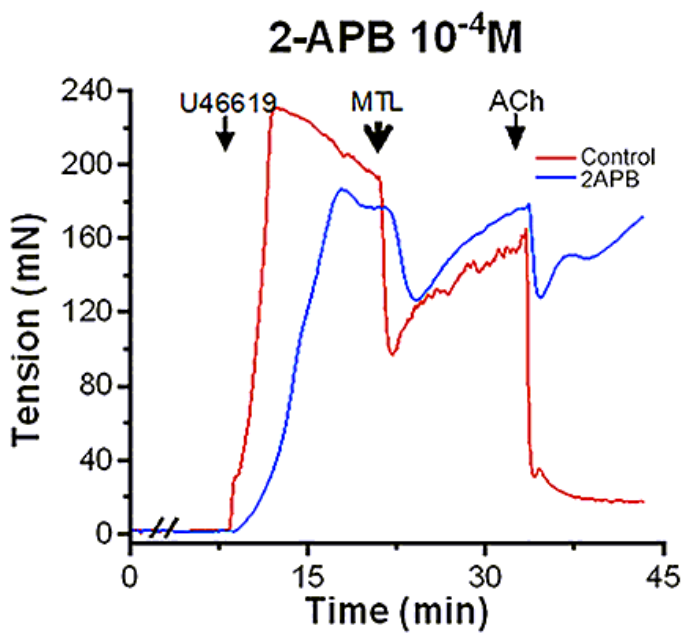

b

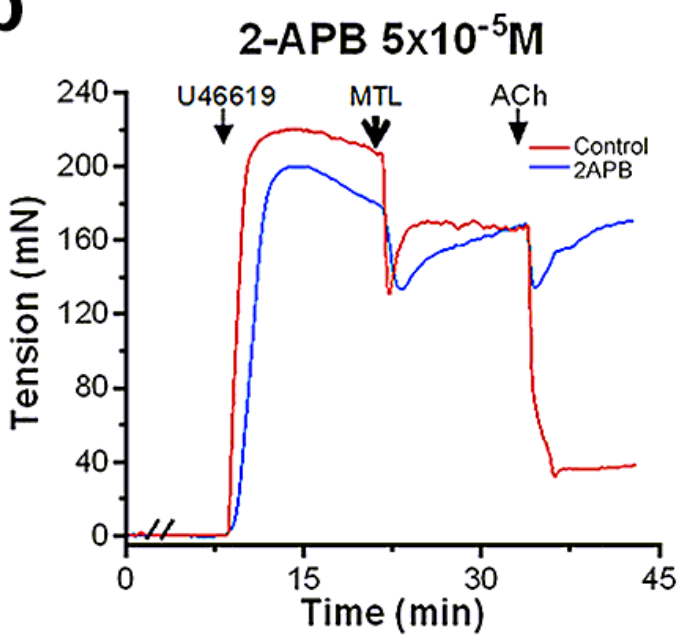

d

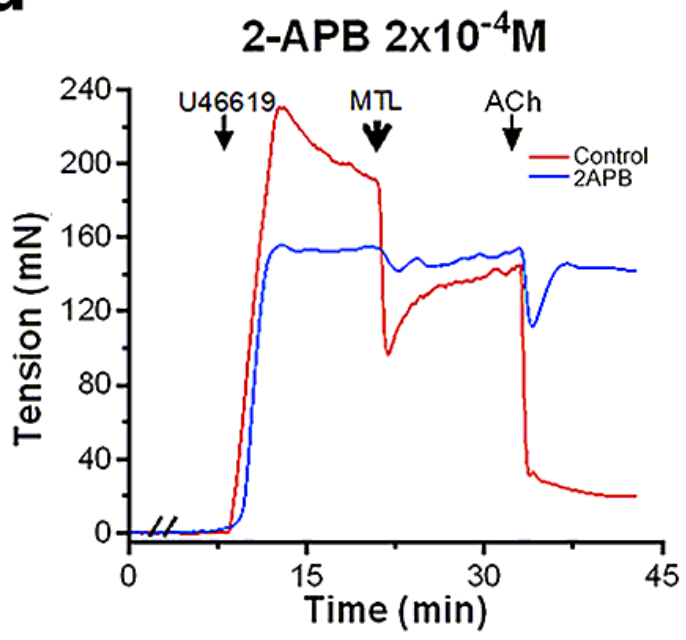

Figure 5

Inhibitory effect of 2-APB on motilin-induced vasorelaxation in U46619 pre-contracted canine LGA rings (a) The concentration-dependent inhibitory effect of 2-APB $(5 \times 10-5-3 \times 10-4 \mathrm{M})$ on motilin $(9 \times 10-8 \mathrm{M})$-induced relaxation with IC50 and HillSlope values. Each point is shown as mean \pm SEM $(n=7)$. $(b-d)$. The original traces of vessels relaxed by motilin $(9 \times 10-8 M)$ with (blue) or without (red) 2 -APB $(5 \times 10-5,10-4$ and $2 \times 10-4 M$, respectively). At the end of each test, acetylcholine was added. The double slash (//) indicates that the blocking process was performed before the addition of U46619. MTL: motilin; ACh: acetylcholine; LGA: left gastric artery. 
a

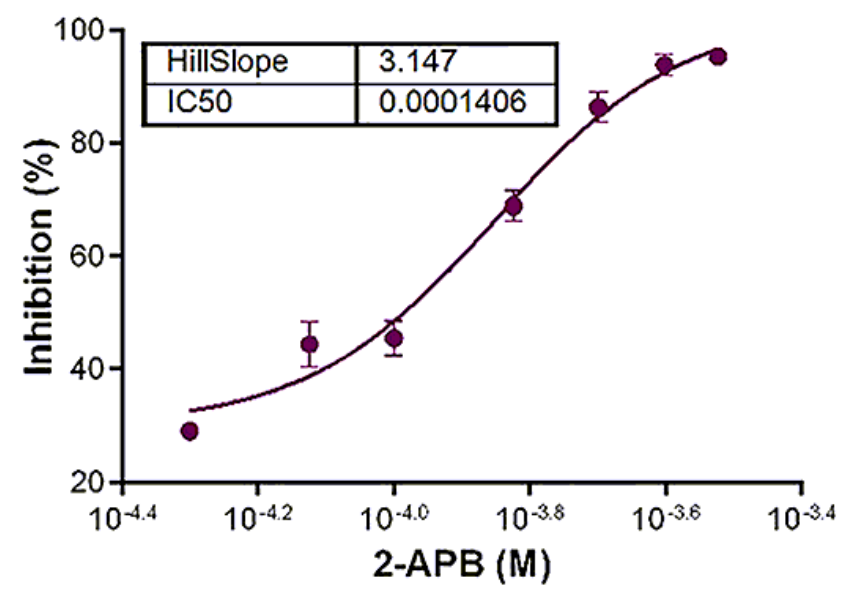

C

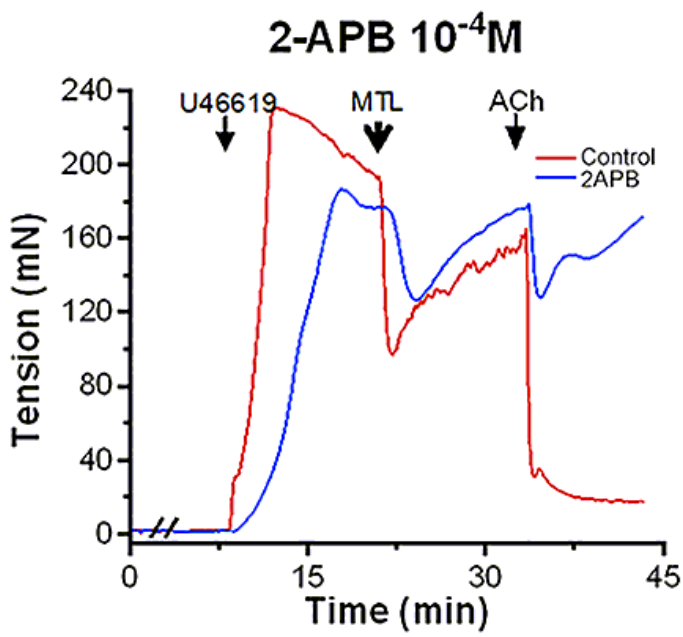

b

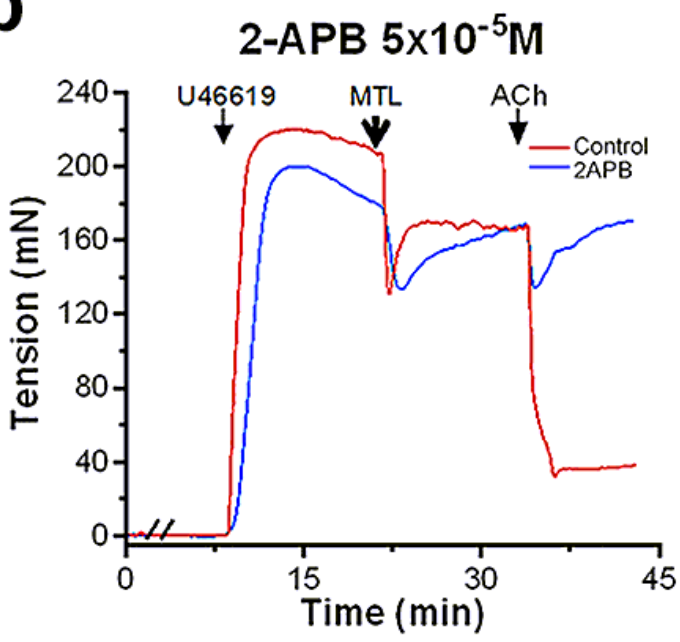

d

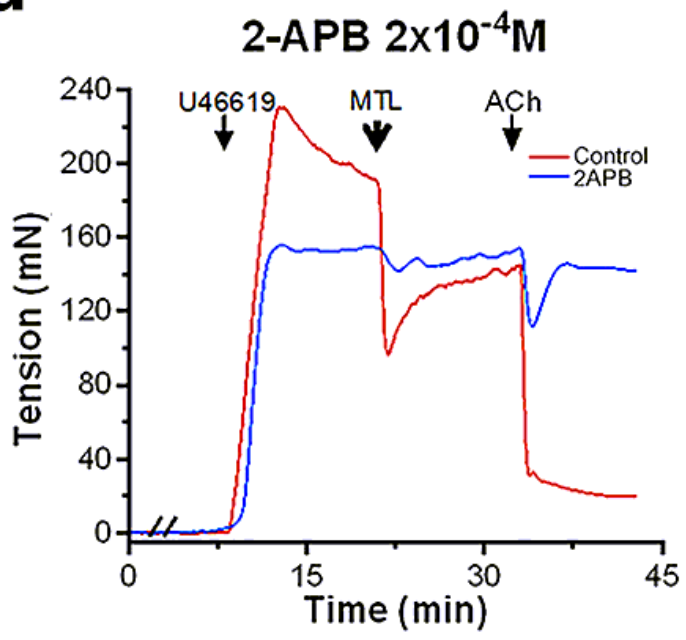

Figure 5

Inhibitory effect of 2-APB on motilin-induced vasorelaxation in U46619 pre-contracted canine LGA rings (a) The concentration-dependent inhibitory effect of 2-APB $(5 \times 10-5-3 \times 10-4 \mathrm{M})$ on motilin $(9 \times 10-8 \mathrm{M})$-induced relaxation with IC50 and HillSlope values. Each point is shown as mean \pm SEM $(n=7)$. $(b-d)$. The original traces of vessels relaxed by motilin $(9 \times 10-8 M)$ with (blue) or without (red) 2 -APB $(5 \times 10-5,10-4$ and $2 \times 10-4 M$, respectively). At the end of each test, acetylcholine was added. The double slash (//) indicates that the blocking process was performed before the addition of U46619. MTL: motilin; ACh: acetylcholine; LGA: left gastric artery. 
a

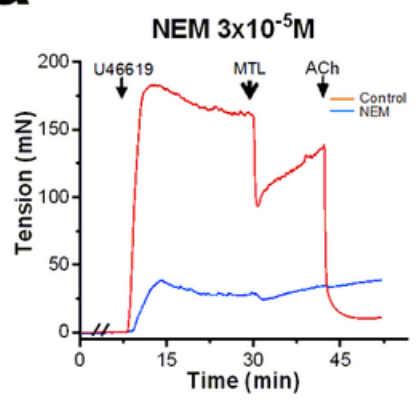

e

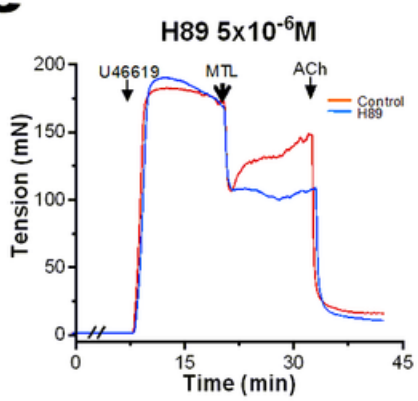

i

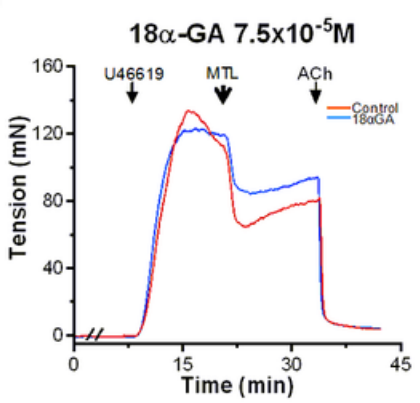

b

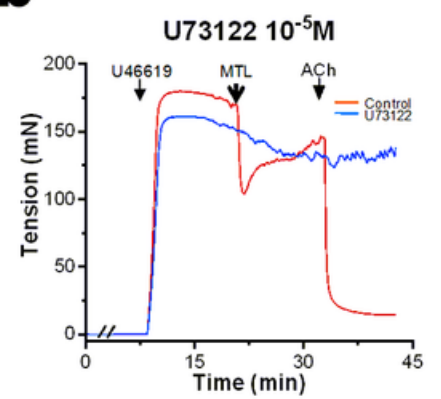

f

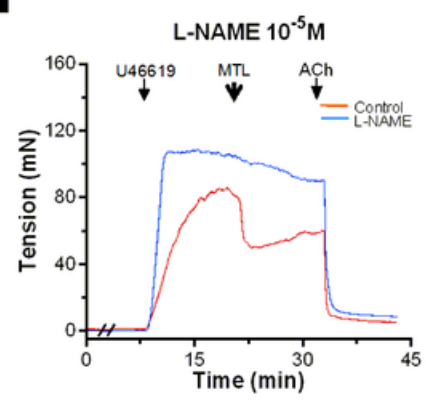

j

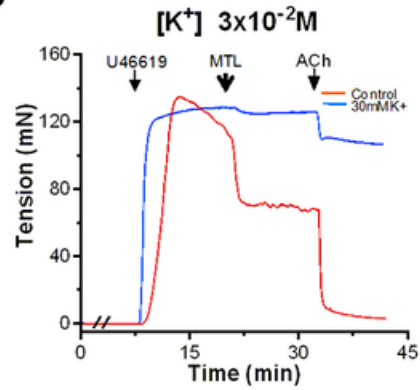

C

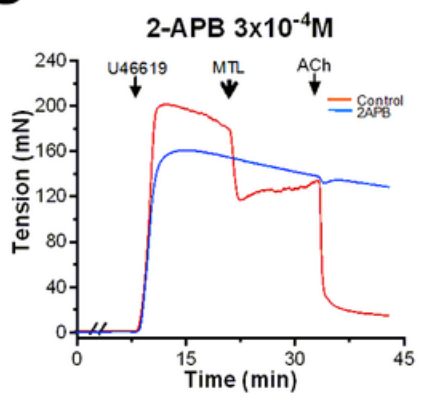

g

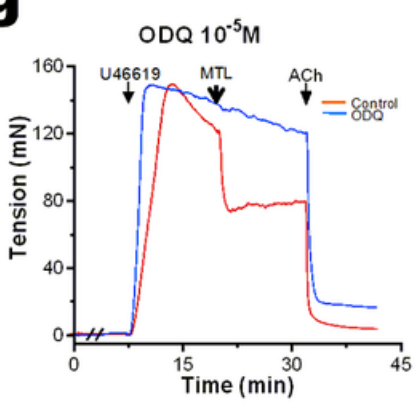

k

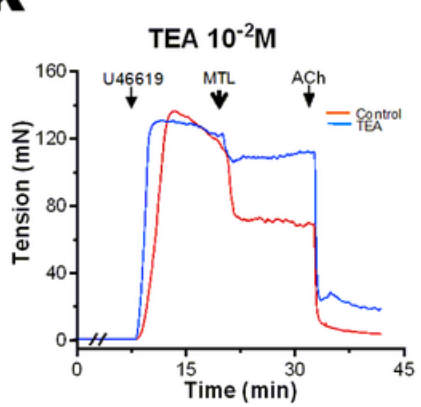

d

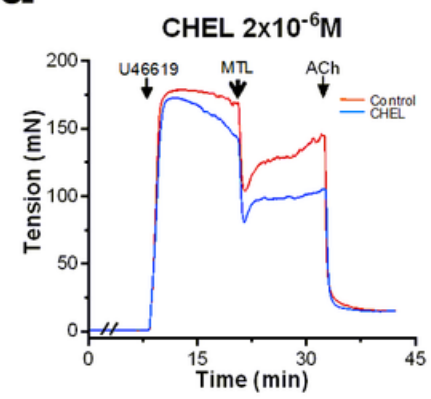

h

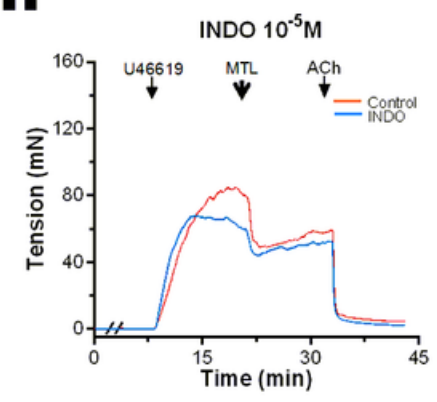

I

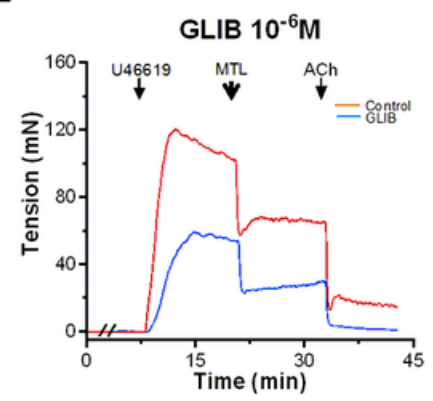

Figure 6

The original traces of motilin-induced relaxation of LGA rings pre-incubated by several inhibitors With (blue) or without (red) inhibitors or blockers the double slash (//) indicates that the blocking process was prior to the addition of U46619. MTL: motilin; ACh: acetylcholine; CHEL: chelerythrine; INDO: indomethacin; GLIB: glibenclamide; LGA: left gastric artery. 
a

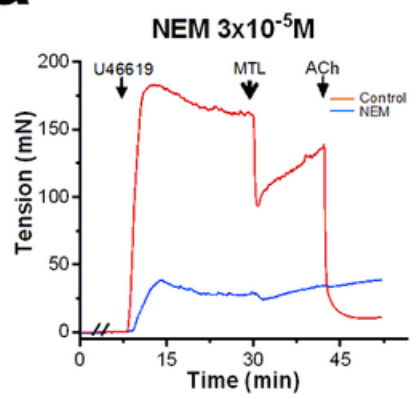

e

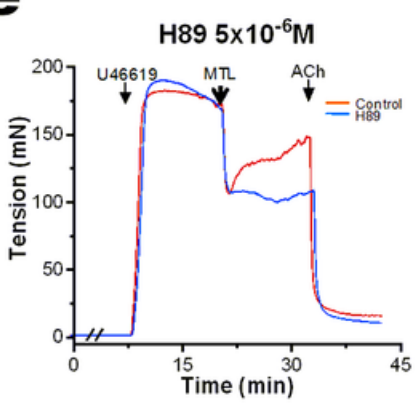

i

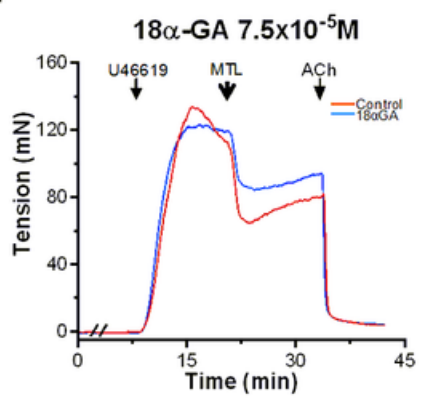

b

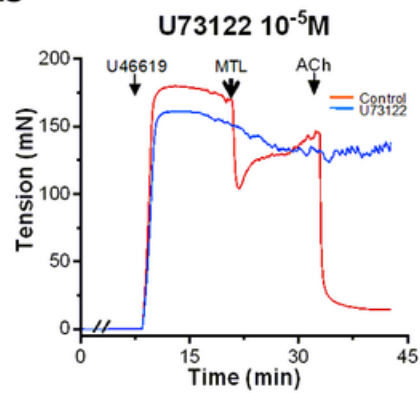

f

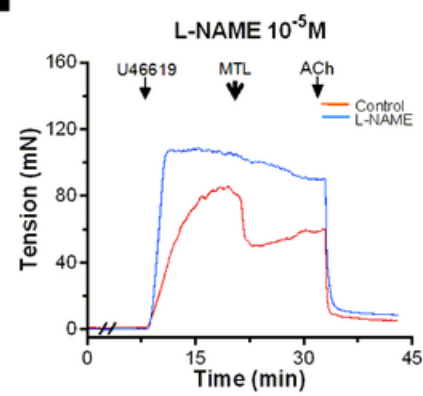

j

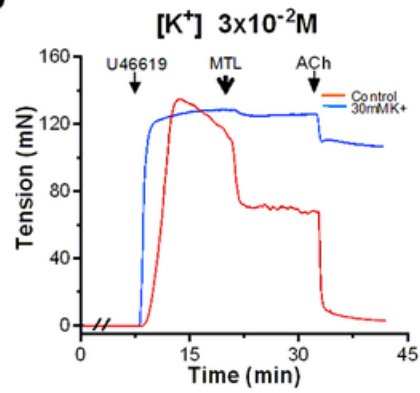

C

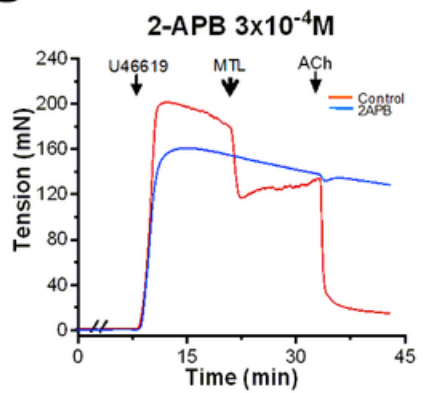

g

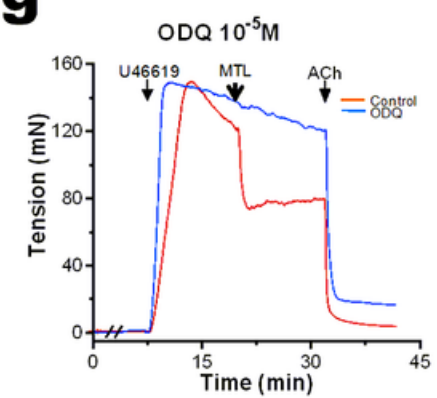

k

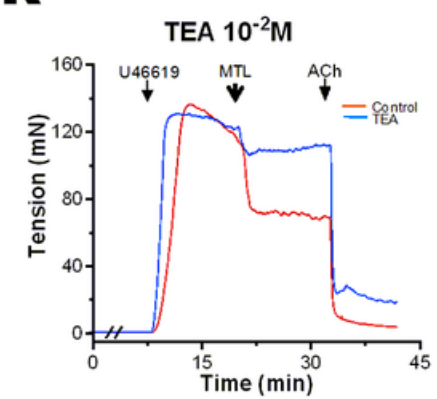

d

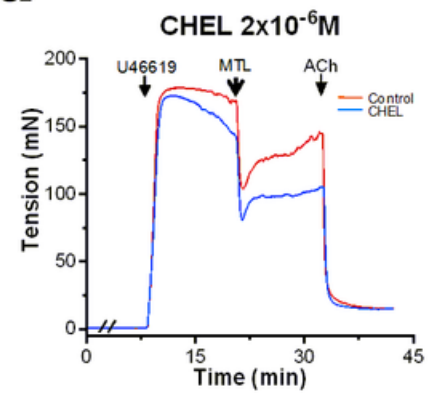

h

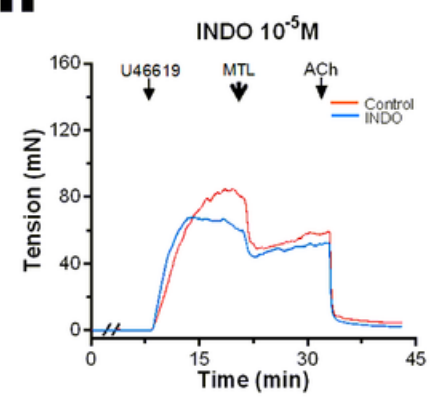

I

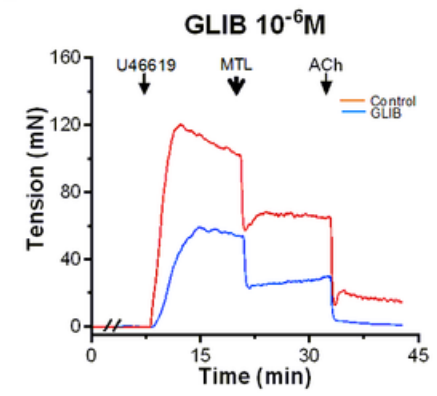

Figure 6

The original traces of motilin-induced relaxation of LGA rings pre-incubated by several inhibitors With (blue) or without (red) inhibitors or blockers the double slash (//) indicates that the blocking process was prior to the addition of U46619. MTL: motilin; ACh: acetylcholine; CHEL: chelerythrine; INDO: indomethacin; GLIB: glibenclamide; LGA: left gastric artery.

a

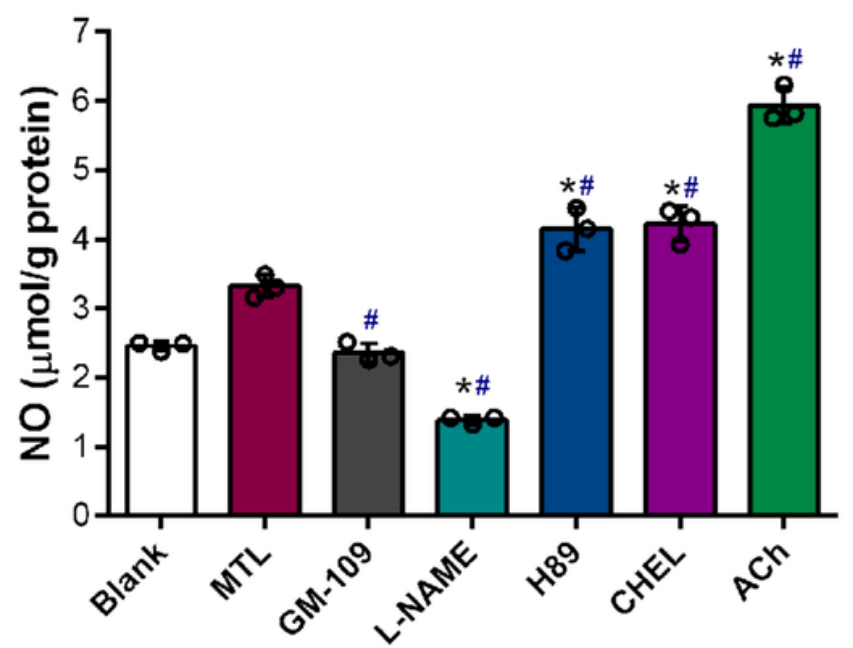

b

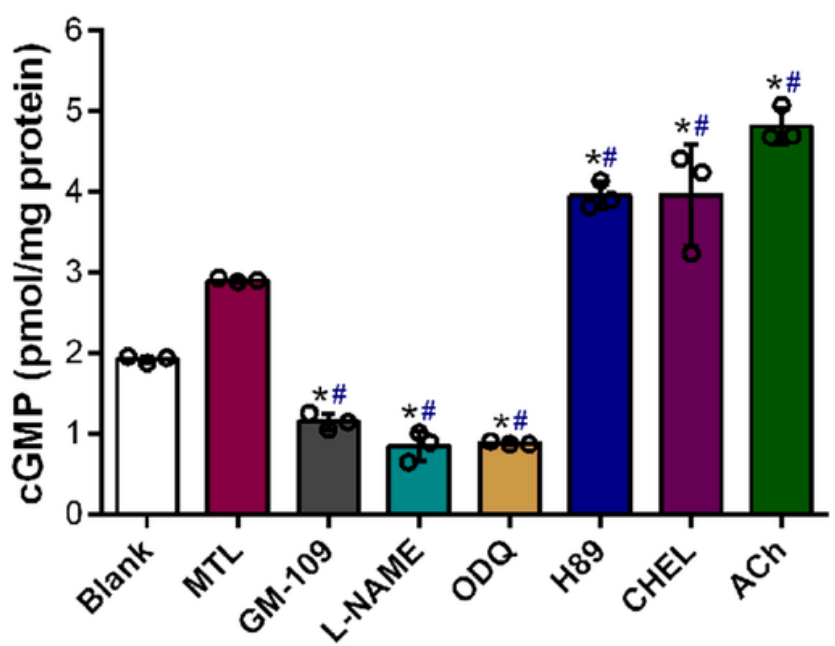


Figure 7

The motilin-stimulated NO and cGMP levels in the tissues of canine LGA (a) Effects of GM-109 (10-5 M), L-NAME (10-4 M), chelerythrine (2 × 10-6 M) and $\mathrm{H} 89(5 \times 10-6 \mathrm{M})$ on motilin $(9 \times 10-8 \mathrm{M})$-stimulated $\mathrm{NO}$ level in U46619 $(5 \times 10-8 \mathrm{M})$ pre-incubated canine LGA tissues $(\mathrm{N}=3$ replicates). (b) Effects of GM-109 (10-5 M), L-NAME (10-4 M), ODQ (10-5 M), chelerythrine $(2 \times 10-6 \mathrm{M})$ and H89 $(5 \times 10-6 \mathrm{M})$ on motilin (9 $\times 10-8 \mathrm{M})$-stimulated cGMP level in U46619 (5 × 10-8 M) pre-incubated canine LGA tissues ( $\mathrm{N}=3$ replicates). In Fig. $4 \mathrm{a}$ and b, compared with the blank or motilin column respectively, * or \# $\mathrm{P}<0.05$ with Dunnett's post-hoc test.

a

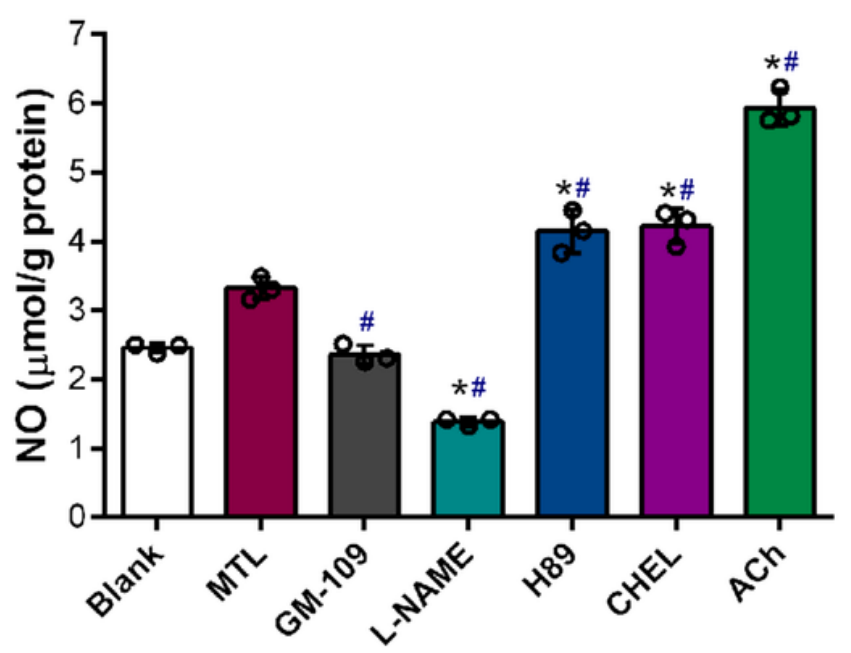

b

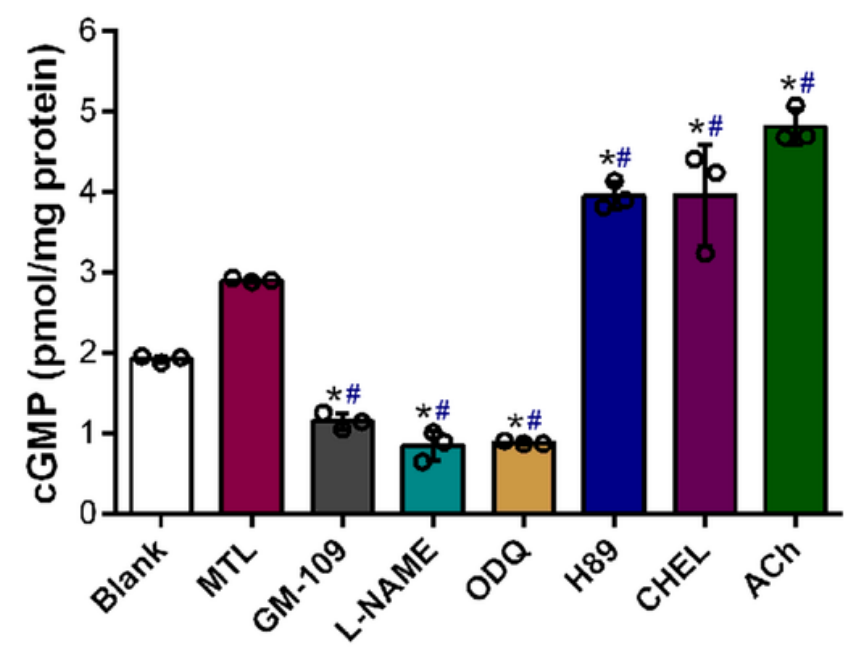

Figure 7

The motilin-stimulated NO and cGMP levels in the tissues of canine LGA (a) Effects of GM-109 (10-5 M), L-NAME (10-4 M), chelerythrine (2 × 10-6 M) and H89 $(5 \times 10-6 \mathrm{M})$ on motilin $(9 \times 10-8 \mathrm{M})$-stimulated NO level in U46619 $(5 \times 10-8 \mathrm{M})$ pre-incubated canine LGA tissues $(\mathrm{N}=3$ replicates). (b) Effects of GM-109 (10-5 M), L-NAME (10-4 M), ODQ (10-5 M), chelerythrine $(2 \times 10-6 \mathrm{M})$ and H89 $(5 \times 10-6 \mathrm{M})$ on motilin $(9 \times 10-8 \mathrm{M})$-stimulated cGMP level in U46619 $(5 \times 10-8 \mathrm{M})$ pre-incubated canine LGA tissues ( $\mathrm{N}=3$ replicates). In Fig. $4 \mathrm{a}$ and b, compared with the blank or motilin column respectively, * or \# $\mathrm{P}<0.05$ with Dunnett's post-hoc test.

a

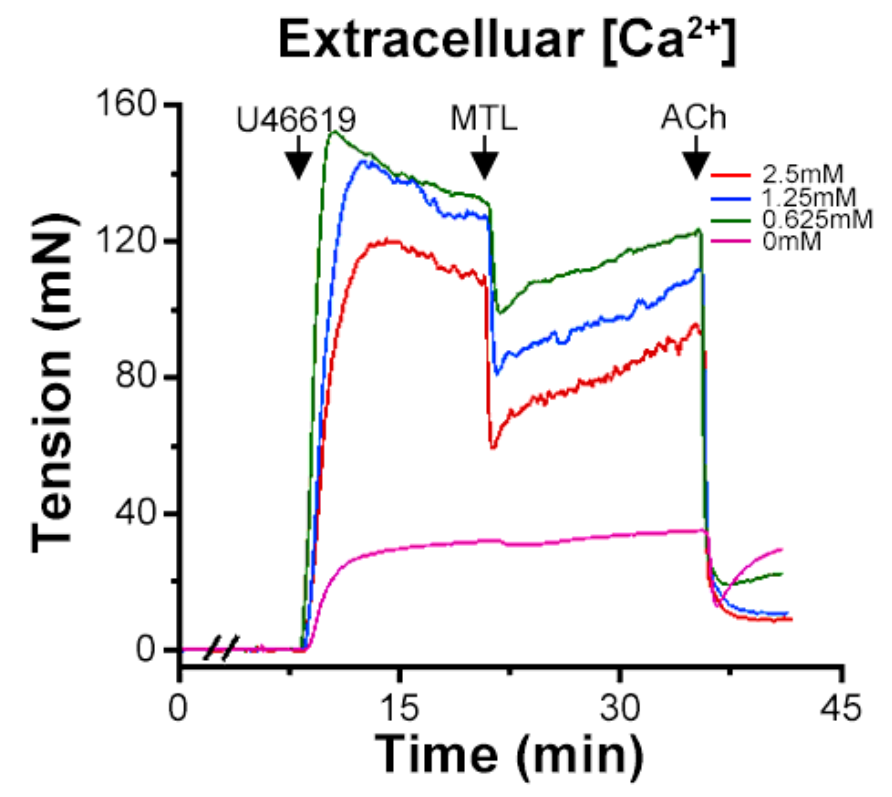

b

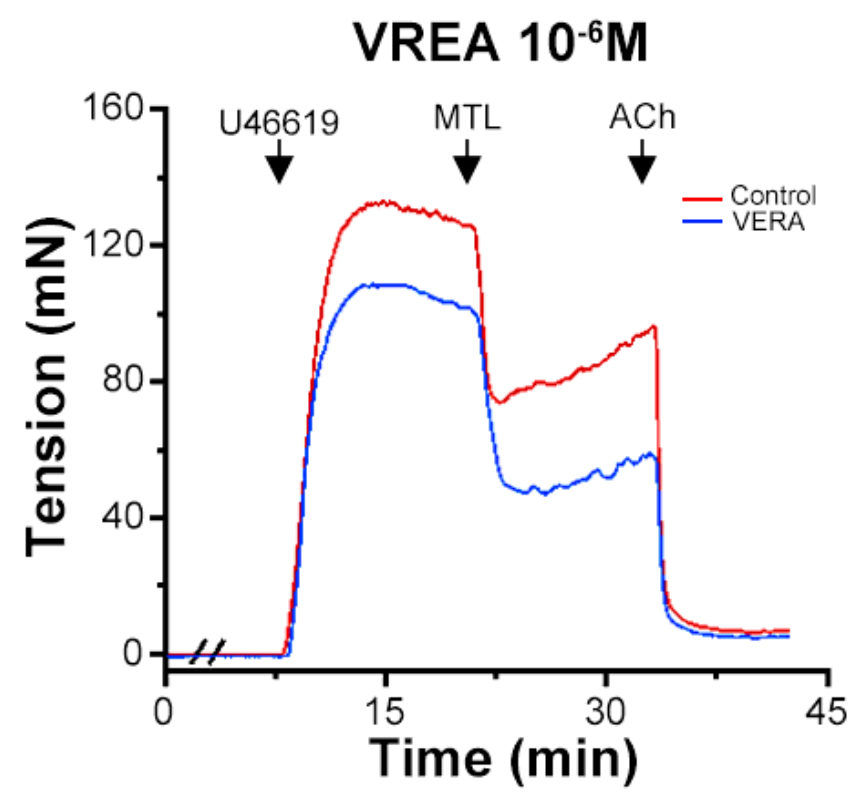

Figure 8

The original traces of motilin-induced relaxation of LGA rings in different extracellular Ca2+ or verapamil (a) The original traces of vessels relaxed by motilin incubated in Krebs solution with $2.5 \times 10-3$ (red), $1.25 \times 10-3$ (blue), $0.625 \times 10-3$ (green) and $0 \mathrm{M}$ (purple). (b) The original traces of vessels 
relaxed by motilin with (blue) or without (red) verapamil. In Figs. S4a and S4b, the double slash (//) indicates that the blocking process was prior to the addition of U46619. MTL: motilin; ACh: acetylcholine; VERA: verapamil; LGA: left gastric artery.

a

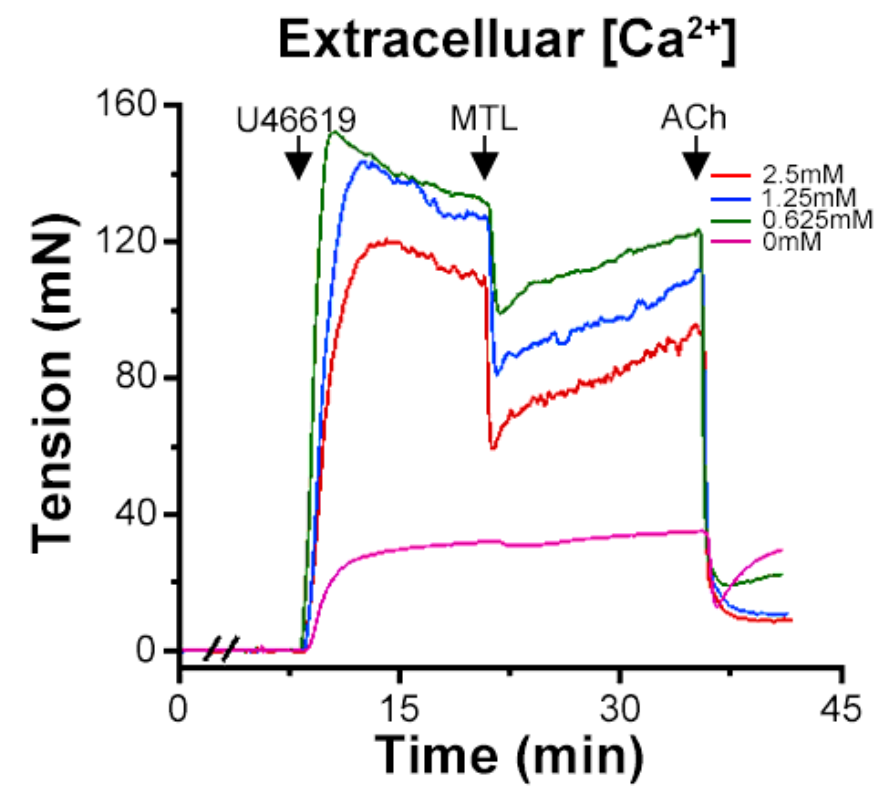

b

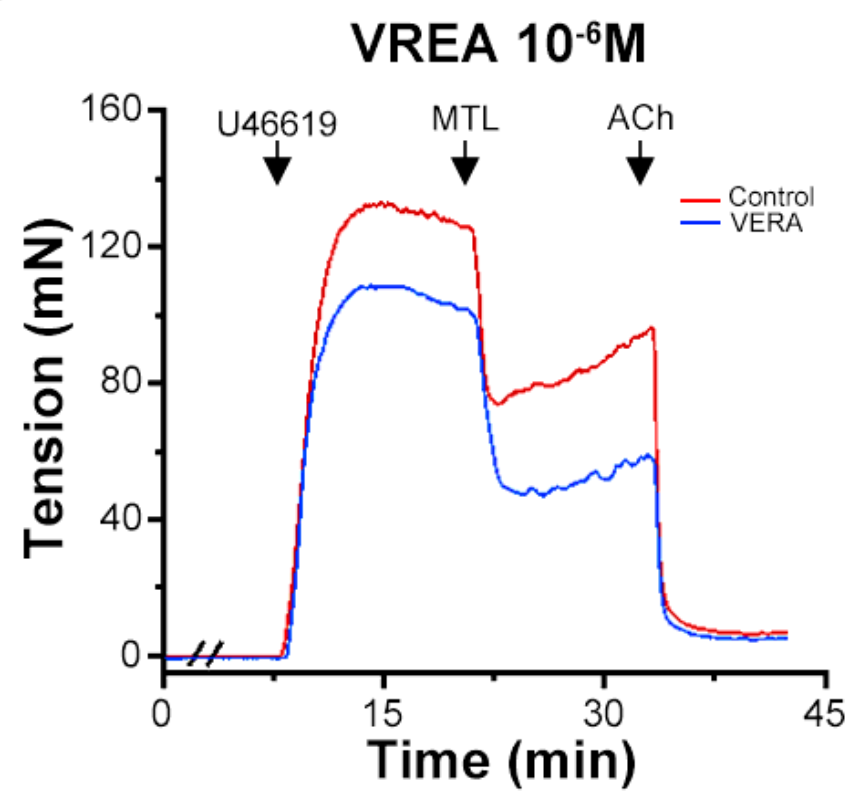

Figure 8

The original traces of motilin-induced relaxation of LGA rings in different extracellular Ca2+ or verapamil (a) The original traces of vessels relaxed by motilin incubated in Krebs solution with $2.5 \times 10-3$ (red), $1.25 \times 10-3$ (blue), $0.625 \times 10-3$ (green) and 0 M (purple). (b) The original traces of vessels relaxed by motilin with (blue) or without (red) verapamil. In Figs. S4a and S4b, the double slash (//) indicates that the blocking process was prior to the addition of U46619. MTL: motilin; ACh: acetylcholine; VERA: verapamil; LGA: left gastric artery. 


\section{Motilin Receptor and Its Signaling Pathways Induced Relaxation of Canine Left Gastric}

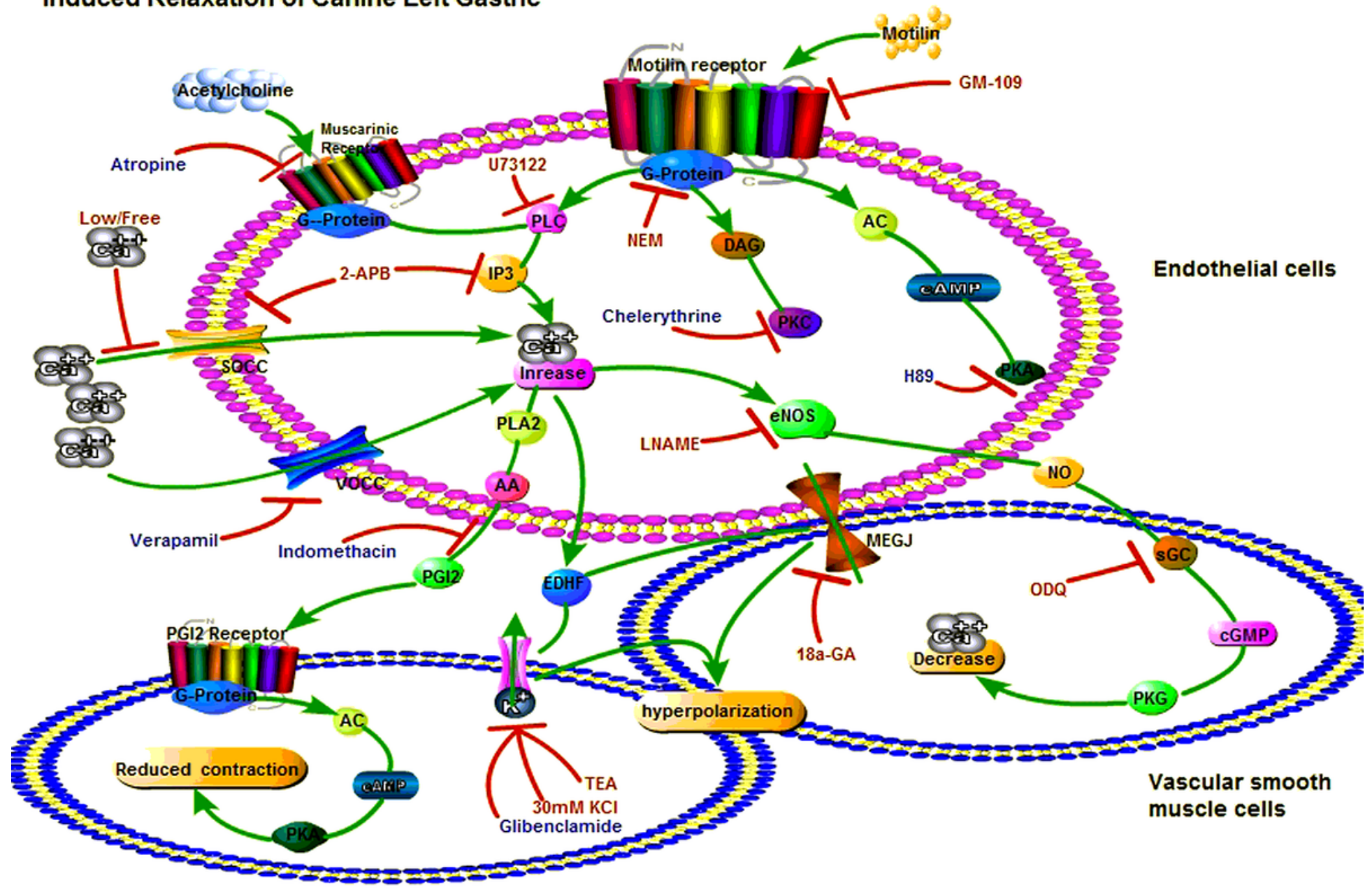

Figure 9

The signalling pathways of motilin receptor in inducing the relaxation of canine LGA. Green arrows indicate the signalling pathways in endothelial and smooth muscle cells during motilin- or acetylcholine-induced relaxation of canine LGA. Red arrows with flat heads indicate the blocking effect on the signalling pathways. The blockers or inhibitors shown in red indicate that the medicines inhibited motilin-activated signalling pathways and those shown in blue indicate no inhibitory effect on motilin-activated signalling pathways. 


\section{Motilin Receptor and Its Signaling Pathways Induced Relaxation of Canine Left Gastric}

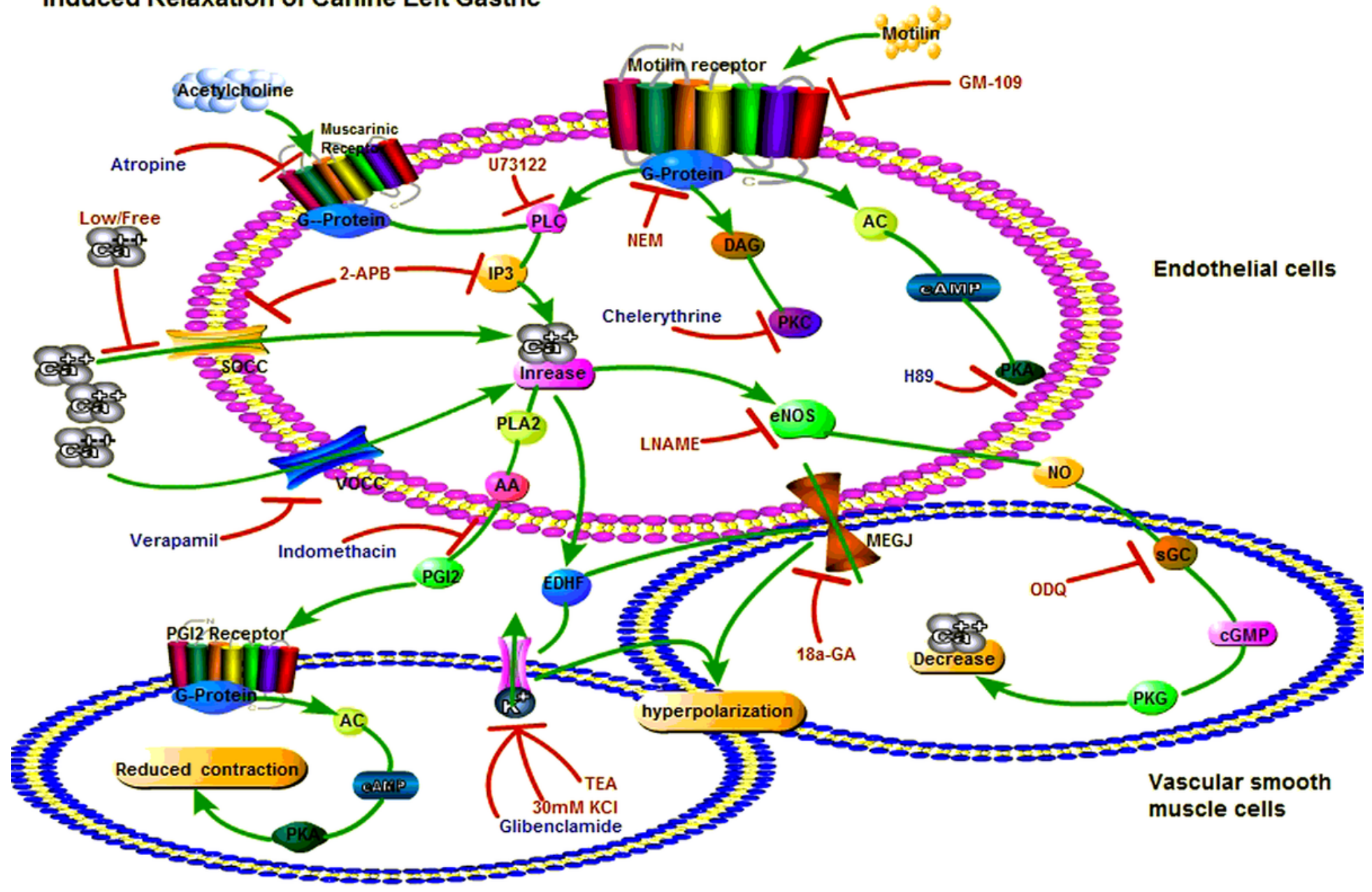

Figure 9

The signalling pathways of motilin receptor in inducing the relaxation of canine LGA. Green arrows indicate the signalling pathways in endothelial and smooth muscle cells during motilin- or acetylcholine-induced relaxation of canine LGA. Red arrows with flat heads indicate the blocking effect on the signalling pathways. The blockers or inhibitors shown in red indicate that the medicines inhibited motilin-activated signalling pathways and those shown in blue indicate no inhibitory effect on motilin-activated signalling pathways. 